Can Gamification Increase Employee Engagement in a New Zealand Context? By

\title{
Daniel McIntyre
}

A thesis submitted to Victoria University of Wellington in partial fulfilment of the requirements for a Master of Commerce degree

Victoria University of Wellington

(2018) 


\begin{abstract}
$\underline{\text { Abstract }}$
Gamification is the application of game principals in non-game contexts (i.e. the workplace). With unsatisfactory employee engagement in New Zealand, gamification is proposed as a possible solution in this thesis. Theoretically, gamification is linked to self-determination theory which recognises that individuals have innate psychological needs (i.e. relatedness, autonomy, competence). The rewards, status, progress through gamification, potentially provides a pathway to satisfying psychological needs, which when fulfilled can foster engagement.
\end{abstract}

Two research questions in relation to gamification were formulated to structure this thesis: How does gamification impact employee engagement in New Zealand? How can gamification be successfully managed within New Zealand workplaces?

Considering that gamification is a relatively new concept within workplaces, the literature gained from an applied search methodology was satisfactory. Four themes and additional content were identified and communicated in relation to gamification and employee engagement. The information extracted from the review was ultimately used to validate and inform an empirical study. Methods to ensure valid research included bracketing, creating an interview schedule, a recruitment plan, and template analysis. In total, twelve in-depth qualitative interviews with employees who had some form of experience with gamification, were conducted for data collection.

To ensure high levels of employee engagement there needed to be a managerial ability to eliminate gamesmanship, clarify gamified rules and purpose, and to promote employee input, otherwise engagement levels would suffer. A framework created within this thesis, the "Gamified Perception Framework", aimed to link managerial actions which equate to both high and low levels of engagement. Employee engagement was also dependent on gamification applications pertaining to employees' psychological needs. To have high levels of engagement there needed to be applications which satisfied specific psychological needs. If gamification applications could not cater to employees' psychological needs, it correlated with lower engagement levels. To communicate the utility of gamified applications a framework was created. The "Gamification Application Framework" attempts to illustrate the impact of the four primary applications utilised within workplace gamification. In addition to the discovery of the two variables, a way to commonly assist in gamification structure was deemed unsatisfactory, an alternative way to generate structure was formulated, and gamified engagement was found to not be generation (age) or industry specific. 
The primary implication of findings was the formulation of a "Five Step Guide to Installing Gamification in New Zealand Workplaces", aiming to assist managers with workplace gamification. The guide provides a method to answer the second research question within this thesis. The guide's multi-step nature is a metaphor for the high amount of devotion needed to manage workplace gamification. Complex in the sense of needing to constantly assess, communicate, and implement gamification when necessary.

Based on findings, gamification can both increase and decrease employee engagement within New Zealand. However, increased employee engagement would require a lot of dedication entailing a high level of professional commitment. Gamification, with serious devotion, can improve the state of employee engagement within New Zealand. 


\section{Acknowledgements}

Finishing this thesis means I have come to a stage where I have ended my time at university. Victoria University of Wellington, the best university in New Zealand, is a place where I have undoubtedly grown. "Vic" has afforded me the opportunities to meet great people, gain confidence, and go outside of my comfort zone.

Firstly with my thesis, I would like to thank Mohammad Saud Khan for being my supervisor. I couldn't have hoped for a better match. Saud gave me time to formulate my ideas and encouraged me to push myself. He was there whenever I needed him, and when we meet I was always uplifted by his spirit.

The staff of Victoria definitely deserves a shout out here as well. All the lecturers and tutors in both my undergraduate and graduate courses were always there for talks after class and during office hours. They gave me a sense of learning which I carried into my thesis. Equally, the professional staff at the School of Management (Garry Tansely, Megan Key, Misa Ito, Luisa Acheson, Celine Ronze etc.) were always organised. If I had a question or a difficulty pertaining to my thesis or general university work, the staff was always fantastic.

Thank you to the people who helped me with my research. The people who set up postgraduate forums (Ruth Weatherall and Dominik Mann) and the interviewees who took time out of their day. I am truly thankful.

Last (but definitely not least!) thank you to my family. My Mum and Dad have always supported me throughout my life. I have never felt an ounce of pressure from my parents and their unconditional love is a driving force in my life. To my bro, thanks for staying up all those late nights and proofreading my university work. The bond we have is special and I can't wait for what the future holds for us. 


\section{Table of Contents}

Chapter One: Overview

1.1 The Context- A Workplace Epidemic ............................................... 1-3

1.2 Gamification- A Potential Workplace Therapeutic ..........................................4-6

1.3 Research Questions................................................................... 7

1.4 Potential Significance of the Research ....................................................

1.5 Structure of Thesis............................................................... 10-11

Chapter Two: Literature Review..............................................12-33

2.1 Conducting the Literature Review, and the Thematic Implications of the Review......12-13

2.2 Gamification's Integration of Technology and Software to Foster Engagement.........14-16

2.3 Gamification's Deployment of Educational Aspects to Foster Engagement..............17-20

2.4 The Ethics Surrounding Gamification can form Barriers to Engagement ...............21-23

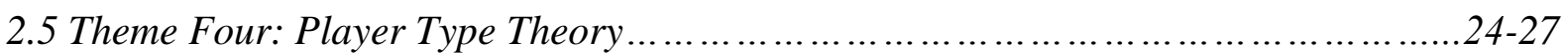

2.6 Additional Literature: Factors that Result in Gamification being Perceived as an

Employee Engagement Tool, which Produces both Faith and Scepticism...............28-30

2.7 A Brief Summation of the Literature Review ...........................................31-33

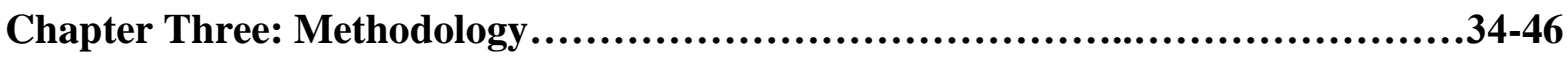

3.1 Introductory Notes and a Brief Look Back at the Research Questions.......................34

3.2 Research Philosophy: What Research Paradigm is Appropriate?...................................35

3.3 Research Approach: Qualitative, Quantitative, or both?.............................................36

3.4 Initiating the Research Design: Choosing a Technique for Data Collection ...............37

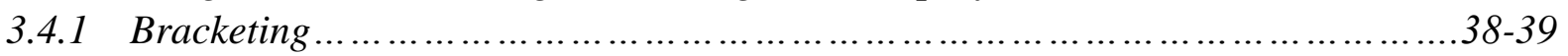

3.4.2 Creation of the Interview Schedule ..............................................40

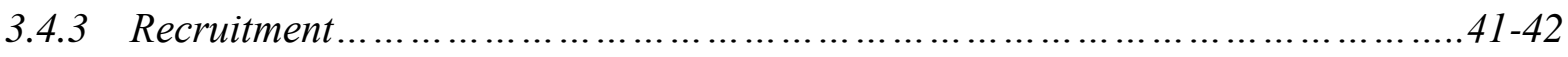

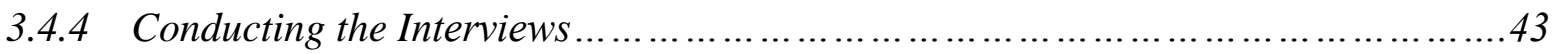

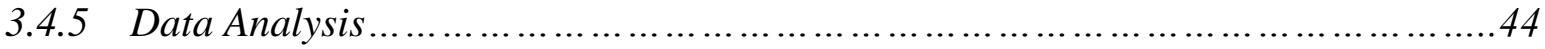

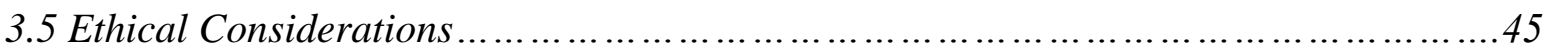

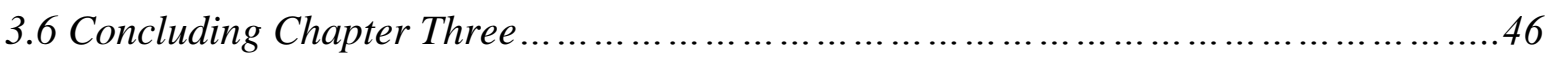




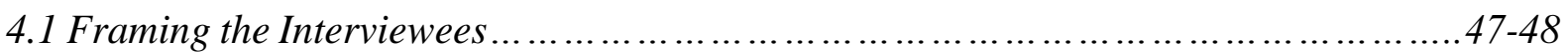

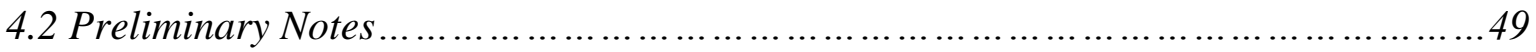

4.3 The Impact of Management Actions within Gamification ...............................50-53

4.4 Framing the Impact of Management Actions on Employee Engagement.................54-55

4.5 Investigating Different Gamification Applications Impact Employee Engagement....56-59

4.5.1 Customisation................................................................

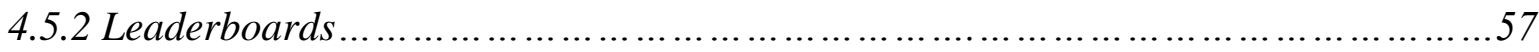

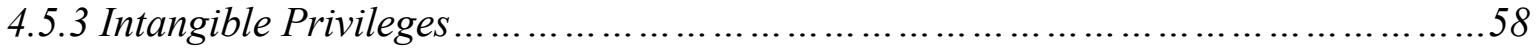

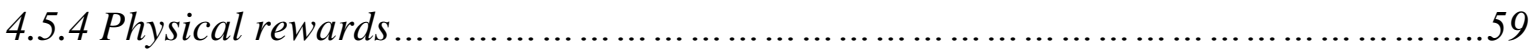

4.6 Framing the impact of Gamification Applications: There needs to be a level of consideration pertaining to employees psychological needs ............................60-63

4.7 Interviewees and their Player Types...........................................64-68

4.7.1 Achievers.........................................................64-65

4.7.2 Free Spirits............................................................65

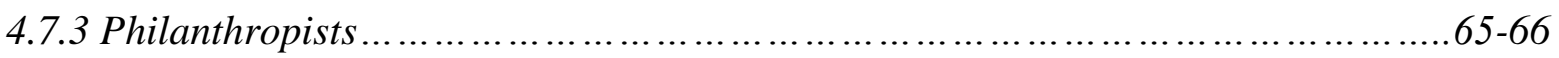

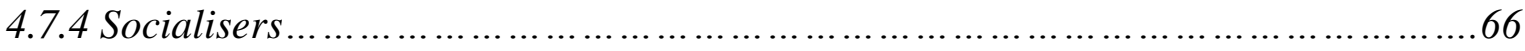

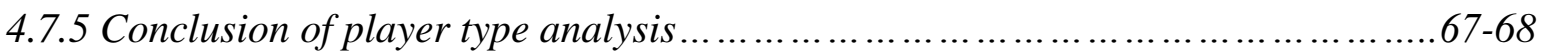

4.8 Gamification and its Alignment with Generations and Work Fields.................69-70

4.9 Concluding Chapter Four ..................................................... 71-72

Chapter Five: Implications of Research........................................73-77

5.1 Practical Implications of the Research ..............................................73-75

5.2 Theoretical implications of the Research.........................................76-77

Chapter Six: Limitations of the Research......................................78-79

Chapter Seven: Conclusions of the Study........................................80-81

References.......................................................................82-93 


\section{Appendices}

Appendix One: Interview Guide............................................94

Appendix Two: Email to Prospective Interviewees.................................95

Appendix Three: Information Sheet.............................................. 96

Appendix Four: Consent Form............................................. 97

Appendix Five: Final Template Analysis Theme Hierarchy.......................... 98 


\section{List of Illustrations}

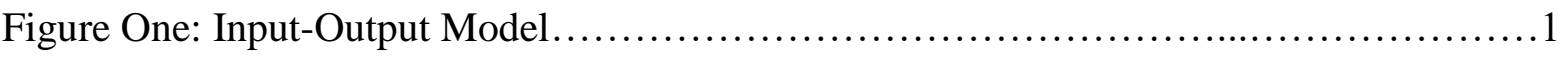

Figure Two: Gallup's Meta-Analysis.............................................2

Figure Three: Findings Table........................................................ 47

Figure Four: Gamified Perception Model........................................ 55

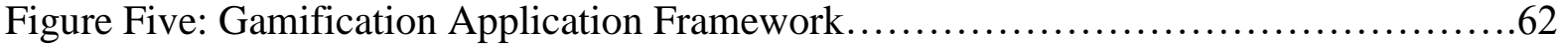

Figure Six: Five Step Guide to Installing Gamification in New Zealand Workplaces........75 


\section{Chapter One: Overview}

The initial chapter of the work you are reading, attempts to introduce and communicate what the essence of this thesis is all about. This thesis attempts to analyse situations, and depict how to potentially improve employee engagement in New Zealand workplaces. Gamification, a concept that has increased in relevance from 2013-2017, is introduced as a work process that could impact employee engagement. Overall, by seeking answers and explanations about gamification, the hope is to arrive at helpful generalisations. Generalisations that can discover if gamification impacts employee engagement in the New Zealand workplace, and generalisations that could extend and create theory relating to gamification.

\subsection{The Context- A Workplace Epidemic}

Abraham Maslow's hierarchy of needs, Kurt Lewin's change model, Michael Porter's generic strategy matrix. Any student of management, would have studied the theoretical foundations of those three models early in their academic education. However, what all those three foundational models and countless others within management address, is the simplicity of the input-output model (Pryor, Humphreys, Oyler, Taneja, \& Toombs, 2011). The core of management has and always will be, transforming capabilities into results, inputs transforming through a work process into outputs. The input-output model in a management context (as seen in "Figure One: Input-Output Model" below) deals with the art and science of executing decisions and evaluating structure (Barton \& Haslett, 2007). When an employee is lacking motivation, a widespread organisational change is paramount, or competitive advantage is desired, the input-output model is always in play.

\section{$\underline{\text { Figure One: Input-Output Model }}$}

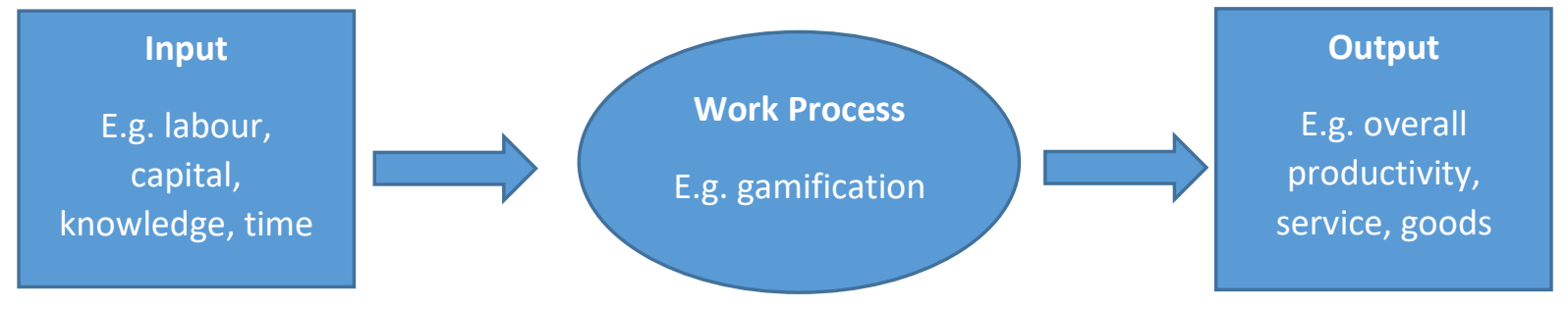

There is no denying that management research over the past decade, has provided both significant theoretical and practical contributions. However, current research over the past ten years has predominately investigated what goes into organisations like employee knowledge and organisational capital, while neglecting the work processes that nurture inputs (Davis, 
2015). A work process is important because it links activities within an organisation, for the purpose of producing a product or service for a user(s) (Leppänen, 2008). Hence, without an effective work process, organisations would find it extremely difficult to create effective value. In fact, a work process can go a long way towards generating significant organisational success. Whether it be Henry Ford's implementation of the assembly line or the widespread application of Lean Six Sigma, work processes play an integral part in accomplishments, and at times shifting business landscapes (Wilson, 2014) (Hess \& Benjamin, 2015).

Amongst a host of factors, the application of the last decade's research direction, has not equated to effective employee engagement in Australasia. The engagement from employees is vital, as it is the emotional commitment a worker has to an organisation and its goals, ultimately dictating employees' productivity within a workplace (Whittington \& Galpin, 2010). Evidence of the troublesome state of engagement in part comes from a survey published in 2013 conducted by Gallup, a respected global performance management company. Gallup's survey indicated that an astounding $76 \%$ of Australasian employees are not engaged at work, with supplemental signs showing no improvement post-survey (Crabtree, 2013) (Hays, 2016). Furthermore, three years after the survey, Gallup's meta-analysis of 82,000 global workplaces indicated the value of an engaged workforce. The meta-analysis found that organisations in the top $25 \%$ in relation to engaged work, significantly outperform peers in productivity and profitability (Please see "Figure Two" for detailed data of meta-analysis) (Gallup, 2017).

Findings, specifically research conducted by Gallup, reinforces the fact that employee engagement is essential for workplace production Figure Two: Gallup's Meta-Analysis

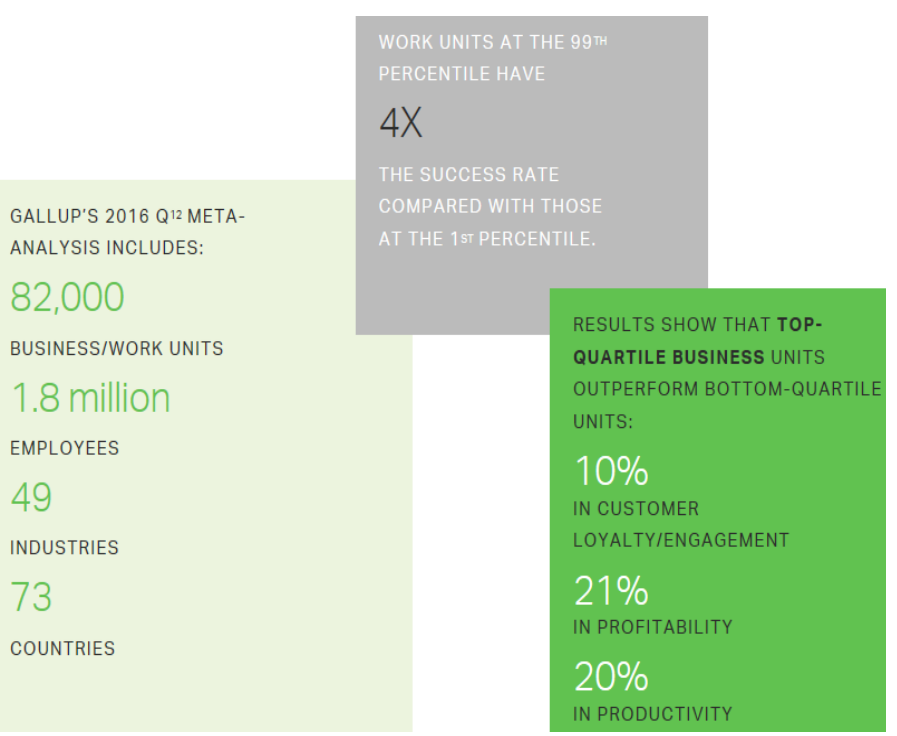

Information extracted from (Gallup, 2016) and success. 
Furthermore, increased employee engagement has been proven to have spill-over effects such as

- Increasing the quality or enjoyment of employees lives (Treuren \& Halvorsen, 2016).

- Positively impacting an employee's impact on others in non-workplace capacities (i.e. an employee's household members) (Rodríguez-muñoz, Sanz-vergel, Demerouti, \& Bakker, 2014).

- Making a manager's job seemingly easier to handle tasks like delegation (Lavigna, 2015).

- Owners of businesses reaping the rewards that high levels of production brings forth (Whittington \& Galpin, 2010).

There has to be a point where a question is universally raised and taken seriously. That question is: with employee capability and organisational resources at their highest capability in history, why has productivity remained noticeably similar to previous generations? Well, that gap between capability and productivity can be explained with employee engagement not experiencing improvement (Incentive Research Foundation, 2017). There must be a way, a potential workplace therapeutic, to increase employee engagement. 


\subsection{Gamification- A Potential Workplace Therapeutic}

All the aforementioned points pertaining to employee engagement, suggests that management research needs to investigate a new direction. A direction that could increase engagement, and therefore employee output, business success, and quality of life. Instead of investigating what goes into organisations, a direction to focus on is exploring work processes that can improve what is already organisationally present. A work process under-researched in the area of management, that has progressively been introduced to researchers over the last four years, is gamification (Campbell, 2016). A simple definition of gamification is, the application of game-design principals and game elements in non-game contexts (i.e. the workplace). Gamification emphasises rewards, clearly stated challenges, and scoring in order to motivate, change behaviour, solve problems, and overall make tasks more engaging (Darejeh \& Salwah, 2016). One example of gamification in the workplace would be, a manager rewarding workers with gift vouchers based on performance. Another example would be employees having the ability to view workplace progress (e.g. number of sales transacted per employee) on an organisational leaderboard in comparison to co-workers. Additionally, as an example, gamification also could entail workers having the opportunity to gain access to special workplace privileges, or in gaming terms "unlockable content", based on performance (Sigala, 2015).

Gamification could be a solution for the undesirable engagement of Australasian workplaces, for one all-encompassing reason. Gamification is congruent with the very environment employees in the western hemisphere have been born, raised, and have been working in over the last 30 years. In the past, in the industrial age individuals were programmed to clock in to execute relatively repetitive, non-cognitively challenging tasks which promoted mass production. But now presently in this age, there is an emphasis on technology, creativity and competitiveness, attributes closely associated with gamification (Noyes, 2015) (Procopie, Bumbac, Giusca, \& Vasilcovschi, 2015). For instance, the days of human assembly lines are dwindling with technology increasingly acting as an automated replacement. Computer generated analytics are acting as an employee measuring mechanism (Gibbs, 2016). Also, we are now living in a world with university courses and organisational departments, devoted to innovation and designed to outflank market competition (Ceira, 2017).

While incorporating aspects of gamification revolving around achievement and status, studies outside New Zealand, specifically in America have shown organisations spanning from e- 
banking to consultancy, experience increases in employee engagement (Rodrigues, Costa, \& Oliveira, 2016). The increase of engagement has largely been attributed to self-determination theory, a macro theory of human motivation. Self-determination theory states that individuals have innate psychological needs (i.e. relatedness: connection with others, autonomy: the ability of control, competence: progressing of skills), that when fulfilled, can foster engagement and create self-regulated behaviour. The rewards, status, and progress through gamification, provides a pathway to satisfying psychological needs (Frost, Matta, \& Macivor, 2015).

Even with evidence of gamification having an impact on employee engagement, there is little empirical evidence exploring the impact that gamification has within the confines of New Zealand. This comes in part, because research into the area of workplace gamification is in its infancy, with researchers minimally investigating gamification's impact in the South Pacific. For further reference, the first recognisable research worldwide focussing on the connection between gamification and employee engagement, was published in 2012 (Neeli, 2012). The encouraging findings of gamified engagement overseas, in a region that is highly relatable to New Zealand in terms of workplace culture (pertaining to Geert Hofstede's updated study of national culture), provides a sense that gamification could positively impact employee engagement in New Zealand (Hofstede, 2017).

Another aspect of gamification is player types. An individual's player type is determined by gaming preferences or motivations linked with different forms of gamification. Gaming preferences or motivations linked with different types of gamification, are thought to be a catalyst to satisfying employees' needs (Kalinauskas, 2014). For example, the existence of an organisational leaderboard may be desired by an employee due to a strong desire for recognition or status amongst colleagues. Research relating to the impact of different forms of gamification and player types is very limited. However, the predominately theoretical work of both Andrzej Marczewski and Richard Bartle, is used as a basis for referencing forms of gamification and player types. Marczewski and Bartle are two esteemed figures in the realm of gamification who have both written about, researched and defined player types (Cheong, Filippou, \& Cheong, 2014) (McCormick, 2013). Their work slightly differs, but draws common ground with the four most predominant player types within gamification (Banfield \& Wilkerson, 2014) (Chou, 2016). 
Briefly, the four predominant player types are:

Achievers: Achievers go to great effort to acquire points and prestige. Achievers favour scenarios in which they're rewarded for completing tasks. Earning the recognition of others through gamified techniques like public leaderboards is important to Achievers (Chou, 2016).

Free Spirits: Free Spirits do not desire to be restricted in work. Associated with creativity, Free Spirits are likely to create the most personal content. Free Spirits wish to gain rewards coming in the form of self-expression and autonomy (Chou, 2016).

Philanthropists: Philanthropists desires to give back to others. Philanthropists have selflessness for others and are driven by an organisational purpose. The motivation for Philanthropists primarily comes from being able to elevate others and feeling fulfilment (Chou, 2016).

Socialisers: Socialisers desire interaction with others. Socialisers are interested in aspects which enable them to accomplish interaction, and will promote internal social networks. The motivation for Socialisers comes from aspects of relatedness (Chou, 2016).

The four player type categories shed light on one of the main difficulties managers have with gamification. Managers find it challenging to design and implement gamification to satisfy all members of a workplace (Marczewski, 2017). Having gamification that pleases a diverse workplace consisting of different player types, can create a significant workload. For instance, evaluating and monitoring gamification in relation to leaderboards, autonomy, relatedness, and philanthropy could entail an overload of assignments. Another difficulty with managing gamification is the potential for unhealthy gamesmanship. Researchers have stated that employees can be so driven by an incentive, whether it be for the use of an item or placing first on a leaderboard, that it influences some workers feeling diminished in relation to co-workers that go extraordinary lengths to "win" (Kim \& Werbach, 2016).

Gamification has the potential to be significantly beneficial for workplaces. However, it should be said that gamification and the management of a gamified workplace is not without caveats. A thesis that explores how gamification impacts employee engagement could provide merit, in terms of increasing productivity and wellbeing. Additionally, exploring how to manage gamification effectively could potentially provide more theoretical and practical substance, in terms of helping guide individuals utilising gamification. 


\subsection{Research Questions}

Gamification in a New Zealand context is uncharted territory. Even so, previous theoretical work and empirical evidence should provide a sufficient base to answer two research questions, which are of interest and value. These two research questions are:

1. How does gamification impact employee engagement in New Zealand?

2. How can gamification be successfully installed within New Zealand workplaces?

The exploratory nature of the research questions above, is the consequent result of a lack of literature finding conceptual distinctions or explanatory relationships (referenced further in "Chapter Two: Literature Review"). Hence, the exploratory nature of the research questions is a result of workplace gamification being considered as a research area that needs a stronger theoretical foundation (Kowalczyk, 2017). The two research questions above provide a pathway to observe gamification in relation to employee engagement and management, to seek greater understanding. 


\subsection{Potential Significance of the Research}

The potential significance/value of the research within this thesis, based on the two research questions, is threefold.

Firstly, the study could be significant, as investigating gamification's impact might provide insight on how to improve the undesirable state of employee engagement within New Zealand. If applications of game principals within workplaces are found to improve engagement, findings could motivate managers with information that acts as a catalyst to elicit productivity and to improve quality of life. In this sense, if more managers install gamification it could change the types of activities within workplaces. Hypothetically, implementing gamification into action would entail workplace activities involving an increased amount of diverse intermediary challenges with unique rewards, potentially altering the face of what we perceive workplaces to be (Procopie, Bumbac, Giusca, \& Vasilcovschi, 2015).

Furthermore, if there are findings that provide strong links concerning implementing and managing gamification, this thesis could provide a framework to help workplaces successfully handle, and reap the rewards of gamification. A potential framework could indicate ways employees experience both increases and decreases in engagement. A framework within this thesis could even provide a guide to installing gamification in workplaces.

The third potential benefit of this thesis, is that findings can assist in testing the theoretical positions of authors/researchers, who have conducted research in the area of gamification. Initially the next chapter, "Chapter Two: Literature Review", can first record the ideas of relevant authors. Subsequently, noted academic ideas can be positioned in reference to research findings in this thesis. Evaluating positions within reviewed articles lends itself to validating, contradicting and potentially extending previous research.

- Primarily validating previous research propositions could entail the need for research, concerning workplace gamification in relation to engagement, to move from an exploratory research area to an area where descriptive research is critical. Proving theories or studies correct, would entail that future research needs to delve deeper into certain characteristics of gamification (i.e. characteristics of gamification-related engagement).

- On the contrary, a strong trend of uniqueness in terms of findings could entail the contradiction of literature. Contradictions would indicate that future gamificationrelated research should be more concentrated on gamification's core research areas (i.e. 
engagement, technology, educational aspects), before any sub-topics are explored (Ruhi, 2015). A more concentrated approach would help researchers gain a greater depth of understanding, potentially needed to pursue investigation into other gamification-related areas

- In reference to future research implications, findings could act as a catalyst for further investigation of gamification in the workplace. If findings show a positive correlation between gamification and employee engagement, it could inspire further research from academics to validate findings. Such research could investigate how age groups react to gamification in the workplace. Additionally, future research could quantify the relationship between gamification and engagement, if gamification progresses from an exploratory research area into a descriptive research area. 


\subsection{Structure of Thesis}

This Master's thesis comprises of seven chapters to structure work. These seven chapters are:

\section{Chapter One: Overview}

- "Chapter One: Overview" has attempted to communicate the essence of this thesis. Overall this thesis will seek answers and explanations in relation to two research questions. The hope is to arrive at generalisations that create value and significance, which can provide solutions, extend theory, and potentially create theory.

\section{Chapter Two: Literature Review}

- "Chapter Two" identifies and records relevant literature, which provides a historical summary of theory and research associated with gamification. A literature review recognises various experts and theories in the area of gamification, therefore providing a suitable platform to validate, contradict, extend, and create academic research in later chapters. Based on literature being strongly linked to distinctive themes, Chapter Two is predicated on a thematic writing approach.

\section{Chapter Three: Methodology}

- The third chapter of this thesis concerning methodology, is all about the description of the research that was conducted for this thesis. Description was informed by findings within Chapter Two (i.e. evidence from authorities or experts pertaining to gamification), to validate and inform an empirical study. Key points and descriptions within Chapter Three include the outline of research design, data collection techniques, and data analysis procedures that were decided to be most suitable for addressing the two aforementioned research questions.

\section{Chapter Four: Findings and Analysis}

- Chapter Four outlines and discusses what research discovered in relation to the two research questions. "Chapter Four: Findings and Analysis" takes a multi-faceted approach to communicate content. Communication includes written text, tables and frameworks. Ultimately, the results or findings contain the facts of the research study. Specifically, two important engagement variables are elaborated on, with additional research observations. The frameworks in this thesis are an unintended 
result of the research, and in this regard, illustrated frameworks were emergent through the process of analysis.

\section{Chapter Five: Implications of the Research}

- "Chapter Five" communicates the implications of research based on the findings presented in this thesis. In presenting both practical and theoretical implications, a specific guide is presented to help answer a research question. The fifth chapter aims to have the ability to inform and provide direction to workplaces and researchers.

\section{Chapter Six: Limitations of the Research}

- The sixth chapter of this thesis, "Limitations of the Research", outlines specific characteristics of research design or methodology which impacted or influenced the interpretation of findings. The content within the sixth chapter attempts to identify the limitations within research, reflect on those stated limitations, and communicate potential solutions to deal with the specified limitations in the future.

\section{Chapter Seven: Conclusions of the Study}

- "Conclusions of the Study" summarises the complex jigsaw puzzle which was this thesis. Chapter Seven provides a chance to take an objective stand and see the work as a whole, with the perception that the pieces of the thesis puzzle have all fitted neatly together. 


\section{Chapter Two: Literature Review}

This literature review will provide a historical overview of the theory and the research literature, associated with gamification in relation to employee engagement. Ultimately, this review will gain evidence from authorities or experts within the research field of gamification. The information extracted from this review will be used to validate and inform an empirical study, detailed in "Chapter Three: Methodology". The content within this review will also act as a catalyst to look back and validate, contradict, and extend research in relation to the findings of this thesis.

\subsection{Conducting the Literature Review, and the Thematic Implications of the Review}

To search for suitable literature, in terms of both validity and quality, the databases "ABI/INFORM Global" and "Web of Science" were utilised. The selection of the databases was due to their comprehensive access to a wide range of quality journal articles. In terms of articles, conference papers, policies, and book excerpts, ABI/INFORM Global and Web of Science had a quality of content that exceeded other databases. The databases utilised for the literature review covered all appropriate content, as unique and simultaneously appropriate content was not discovered on other databases. It should be noted that in conjunction with the two utilised databases, searches were conducted on the search engine "Google". Articles, papers, policies and book excerpts from literature linked to important information that could be found through a Google search. Thus, Google resulted in valuable topic related non-database information.

Searches on ABI/INFORM Global, Web of Science, and Google were conducted in an iterative manner during early November 2016 to mid-February 2017. The database searches revolved around the input of three keywords. These words were "gamification", engagement", and "workplace". The keywords were chosen on the basis that those terms best related to the thesis topic, which in turn led to the discovery of valuable topic-related content. Since topic-related literature was sparse, due to workplace gamification being a relatively new concept, all literature was reviewed unless articles were perceived to be off-topic. Some literature was determined to be unsuitable to review by reading the titles and abstracts of searched content. An example of what was deemed inappropriate content, was an article on a completely different topic (i.e. text mining) referencing aspects of gamification very briefly (Joorabchi, English, \& Mahdi, 2016). The search methodology utilised resulted in 65 articles, 4 conference papers, and 15 web links being carefully reviewed and referenced for this thesis. 
Considering that gamification is a relatively new and untapped concept itself, the literature gained from the applied methodology was satisfactory. The reviewed content came from respected journals (i.e. International Journal of Innovation, Management and Technology) and provided valuable topic-related information. The revised content ultimately related to factors concerning gamification and employee engagement, in a workplace context directly and indirectly. Content interestingly related to four themes. Those four themes were:

1- Gamification's integration of technology and software to foster engagement

2- Gamification's deployment of educational aspects to foster engagement

3- The ethics surrounding gamification forming barriers to engagement

4- The description and impact of the four predominant player types within gamification

The searched literature's strong link to the four themes listed above, consequently influenced Chapter Two to be written thematically in separate sections. Writing the literature review thematically in this thesis, entailed a review organised around four topics or issues (as seen above), opposed to a review completely reliant on the progression of time. Although, the progression of time was still acknowledged in this review. Within all four themes, content was ordered chronologically when appropriate. Ultimately, the four themes, with a section for additional notes, were deemed to cover all of the relevant material needed to inform an empirical study. 
It is acknowledged that employees are influenced by their workplace surroundings, or certain workplace characteristics. Surroundings and characteristics shape assumptions through key social and cultural trends, therefore how employees view the world, commitment, and authority. For instance, looking back in the 1960s, the workplace was influenced by an emerging managerial focus on team-oriented behaviour. But now, what has defined the workplace of the present has been the emergence, utilisation and abundance of technology and software, to further both team-oriented and individualistic behaviour (Gibson \& Sodeman, 2014). The high utilisation of technology and software, is likely familiar to any twenty-first century employee who has operated in any office around the globe. For example, not only are employees expected to use computer gadgets on location, but additionally $59 \%$ of employed online adults take their occupations outside of the physical workplace (Purcell \& Lee, 2014). From organisational intranet to online scheduling apps, workplaces have been truly reshaped by the new information pathways which have been created (Kapko, 2016). The modern-day dependence of technology and software relates to the first theme of this literature review. Gamification's modern-day birth within workplaces, has corresponded with an integration of technology and software to foster employee engagement.

Research exploring gamification's integration of technology and software, was not investigated in a narrow-scope until the year 2015. What influenced the specific research area, was global organisational findings which discovered that employees have the ability to respond optimally, in terms of quickness and efficiency, with technology. The access to new technology and software, which has improved communication systems (e.g. video conferencing applications like Skype), has been seen as a catalyst to achieve a common goal. Whether that goal is inspiring employees to cooperate as a team to formulate a marketing plan, or send a collaborative business proposal via email (Aharonson \& Schilling, 2016). Overall, the collaborative impact of technology and software has made managing the social dynamic, preparation, and hierarchies of online systems essential. Each action, even a minor assignment has a purpose and fits into a wider framework. The specific idea is, gamified technology and software act as a competitive communication system which helps people perceive they are part of something whole, greater than an individual level. Consequently, the potential synergistic engagement which gamified technology and software can bring forth, acted as a catalyst towards investigative intrigue and subsequent examination (Kalinauskas, 2014) (Shpakova, Dörfler, \& MacBryde, 2017). 
What helped initiate a more concentrated focus on technology and software relating to gamification, was Marianna Sigala's undeniable research contribution in 2015. Sigala's research executed a case study approach concerning the successful software design of TripAdvisor's website, specifically the website's utilisation of game mechanics in non-game contexts. Overall, Sigala found that Trip Advisor mobilised and triggered virtuous reciprocal effects on their website, which resulted in continuous customer communication to ultimately attract travellers and encourage reviews. Success was executed with TripAdvisor's conversion of website software functions (i.e. user reviews that can contribute planning and interaction with others), into "play" tasks. The website's updated provision of points and badges for user reviews, ultimately resulted in a higher level of user engagement. The increased engagement was found to be a consequent result of enhanced psychological outcomes, in relation to there being the most common of game rewards (i.e. status from points and badges) and experiential conditions (i.e. increased interaction capabilities) (Hamari \& Eranti, 2011) (Xu, 2011). Higher engagement from users resulted in the accomplishment of attracting new website users, and further stimulating the motivation of travellers to remain engaged with website services. Even though Sigala's paper predominately focuses on customers or users in relation to gamification, an important question was reached which generated future research. That question was, how does gamification motivate in a broader business context, specifically in the area of employee engagement (Sigala, 2015).

Sigala's findings and the increasing publicity around gamified technology and software, inspired important research and action in relation to the employee side of the workplace. It was constantly hypothesised that gamification had an enormous potential to engage individuals, but research lacked evidence in terms of the relationship between technology and employees (Zichermann \& Linder, 2010). That lack of evidence changed when strategy enthusiast Andy Campbell, used the same case study approach to investigate employee engagement at a renowned computer tech company, named Oracle. It was discovered that Oracle utilised gamified technology that tracked productivity and rewarded employees with privileges based on results. At Oracle, privileges included the use of standing desks, cycle-to-work arrangements, gym affiliations and on-site mindfulness classes. A consequent result of Oracle's use of gamification was that employees were found to be more engaged at a personal level. With a higher level of engagement, there was greater employee commitment at the computer tech company, therefore greater productivity (Campbell, 2016). 
Although research is limited, the exploration of gamified technology and software has opened the doors to other real-world implementations, with the intention of increasing employee engagement. Implementations that are successfully happening in 2017, which could influence workplaces adopting gamification at a higher rate. For instance, Electronic Arts (EA) have continuously refined their internal training program, EA University, based on trial and error. The very aim of EA University itself, is to train and engage employees by utilising gamification. Interactive software within EA's program, has allowed employees to solve challenging game based problems to gain points/prestige, and to successfully collaborate with other employees/players. The autonomy given to employees to solve and master challenging problems as part of training, has so far appealed to employees intrinsic motivations and fostered high levels of engagement (Lowman, 2016). EA University is just one notable organisation incorporating gamification along with others including Deloitte, a notable professional services firm. Deloitte currently uses software that creates virtual employee profiles and achievement systems to motivate employee productivity. Deloitte's gamified software has directly correlated with employees increasing their participation in training programs, projects, and volunteer activities to ultimately earn achievements that attach to virtual profiles (Ruhi, 2015). Deloitte has even extended themselves, to incorporate gamified software for recruitment of prospective graduates in New Zealand to critical acclaim. Deloitte's "pick a path" interactive video journey, provides prospects with the chance to perform a series of game-based choices, in which their decisions are evaluated (Rapt, 2017).

The information communicated concerning gamification's integration of technology and software, provides insight into how companies have approached gamification to engage employees. Research findings noted, indicate employee engagement occurring based on the utility, exposure, and external application of technology and software. The utility, exposure, and external application, deliver clear signs of increased engagement at a workplace level. A thesis attempting to answer the two research questions outlined in "Section 1.3", must attempt to examine and analyse gamified technology and software in a New Zealand context. 


\subsection{Theme Two: Gamification's Deployment of Educational Aspects to Foster Engagement}

Renowned South African Activist, Nelson Mandela once said: "Education is the most powerful weapon which you can use to change the world" (Mendelson, 2016). The $16^{\text {th }}$ President of the United States, Abraham Lincoln once said: "Upon the subject of education ... I can only say that I view it as the most important subject which we as a people may be engaged in" (University of Michigan , 2001). In relation to gamification, it appears based on literature, that educational aspects are being deployed for positive change in employee engagement. Research suggests that gamified applications in the workplace (i.e. public organisational leaderboards) and the aspects behind those elements, act as educational prompts. Prompts in the sense that employees have a greater ability to learn and engage when exposed to game elements. Over the last four years, authors have explored what educational aspects exist within gamification, and how those aspects have evolved (Al-Azawi, Al-Faliti, \& Al-Blushi, 2016). The deployment of educational aspects within gamification, concerns the second theme of this review.

Before delving into the specificities of the most contemporary educational aspects being deployed in gamification, it is important to realise the recency and evolution of this research area. The first significant research exploring the education aspects deployed within workplace gamification, was published in 2012. In 2012, there was an investigation into the psychology of why games encourage participation (Vassileva, 2012). Fundamentally, initial research relied upon two well-known economic ideologies, to explain strategies used for motivating individuals concerning gamification. The two well-known economic ideologies communicated were

- The Classical Rational Economic Perspective- The first real approach managers utilised to engage employees in gamified workplaces, was thought to be based on rational economics. The rational economic ideology in a workplace context, approaches the issue of motivation by assuming that employees are rational individuals. Rational in terms of taking actions to completely maximise utility/satisfaction. The goal of successful gamification in relation to the rational economic perspective, is to design particular rules. The aim of rational rules is to ensure that an overall system in place (i.e. workplace) fulfils a goal(s), and optimises all participants (i.e. employees). In this rational regard, you could use the example of a workplace where everyone is competitive, in which an organisational leaderboard is installed. The leaderboard would be intended to ensure a fair chance 
for employees to maximise their individual utility, by being recognised through rising above competition. However, while the rational perspective sounds ideal, there is one overarching problem in relation to workplace gamification. The rational perspective does not take the diversity of employee motivations which exist within workplaces, into account as not all individuals are rational. For example, some employees do not have a competitive nature and are content not being on "top" in a workplace environment. In turn, a person's will to not pursue maximum utility in their work life, may mean that the promotion of competition through a leaderboard equates to a decrease in motivation. Overall, the rational perspective and corresponding workplace gamification designs, do little in considering motivations on an individual basis (Vassileva, 2012) (Baptista \& Oliveira, 2017).

- The Behavioural Economic Perspective- Once the rational approach to gamification was not perceived to increase productivity, behavioural economics was used as a basis to approach workplace gamification. The behavioural economic perspective in a workplace context, views people as irrational and investigates the social, cognitive and emotional factors in understanding the decisions of employees. For instance, behavioural economics concerns psychological phenomena, such as "reciprocal altruism", which contradicts the rational perspective's assumption of utility maximisation. Ultimately, the behavioural perspective considers the individual motivation of employees to be extremely differentiated. Ultimately, behavioural economics suggests that gamification cannot happen in "one for all" working environment. Conversely, gamification concerning the behavioural ideology, has to be considerate of the individual motivations within a workplace in order to increase the engagement of all employees (Vassileva, 2012) (Baptista \& Oliveira, 2017).

The evolving perspective from utilising rational aspects to behavioural aspects, communicates the importance of employee consideration. The development communicates that gamificationrelated engagement, needs a careful consideration of all employees individually. A consideration that enables effective communicative competition, that has been theorised to improve performance (Kapp, 2012) (Hamari J. , 2013). However, that kind of all-encompassing consideration, which in theory best positions a gamified workplace to increase engagement, is 
at times difficult to execute (Hamari, Koivisto, \& Sarsa, 2014). The difficulty lies within the fact that most workplaces consist of employees who greatly differ in a multitude of aspects. The problem specifically lies in having to cater to a diversity of desires, entailing a multifaceted approach. Managers cannot just rely on a singular application of gamification (e.g. leaderboard utilisation), as not all employees are competitive. Instead, since employees have a range of desires there needs to be the incorporation of multiple gamification applications (e.g. leaderboards plus unique privileges plus incentivising rewards). Furthermore, having to monitor, analyse, and distribute across a multitude of gamified applications, is not without serious effort, can be time-consuming, and potentially stressful for a management team (Kumar, Herger, \& Friis Dam, 2017). Based on the difficulties approaching gamification, researchers have attempted to further investigate what educational aspects motivate optimal behaviour in gamified environments.

Jung Tae Kim's and Won-Hyung Lee's recent academic research in 2015, pioneered into exploring the dynamics of educational aspects within gamification. Based on prior research involving general game design features, Kim's and Lee's work identified four primary educational characteristics, which were hypothesised to influence the effectiveness of learning within gamification. Those four characteristics were curiosity (e.g. hidden workplace privileges), challenge (e.g. organisational leaderboards), fantasy (e.g. customisable avatars) and control (e.g. increased autonomy). What made the Korean academics work of additional value, was the conclusion reached at the end of their article. The academics concluded, that based on the promotion of curiosity, challenge, fantasy and control, gamification was superior relative to traditional ways of learning. Traditional in the sense of commonly utilising whiteboards, textbooks, and face-to-face classroom activities with human instructors to engage individuals. Gamification being perceived as a way to promote superior engagement, was based on findings pertaining to the progress of achievement in relation to time. In terms of traditional learning methods, achievement within the 2015 study was displayed as a linear equation with respect to time (or effort). In general, traditional methods were found to increase achievement for an initial period. But after that initial period, achievement did not continually increase. Conversely, it was discovered that gamification involving the four main educational characteristics, can result in continual improvement (Kim \& Lee, 2015). At the time of Kim's and Lee's published work, additional papers began to provide credence to the authors' findings. Acknowledgement that serious games have positive effects in educational contexts, and learning performance (Jong, 2015). 
Based on elements of Kim's and Lee's work, three academic authors investigated the effectiveness of gamification, in relation to employees' educational development. The research was predicated on the observation of employees navigating through gamified talent assessment processes. Processes involving "levelling up", feedback, and involvement in collaboration activities which promoted competition. The three authors' 2016 study yielded some interesting findings. The aspects of gamification (i.e. curiosity, challenge, fantasy and control), were successfully being utilised to not only educate talent, but identify high-level talent. It was discovered that gamification processes enabled individuals to become more adept in terms of innovation, being responsive in uncertain environments, and thriving in states of frequent change. However, it was theoretically acknowledged that the degree of effectiveness is dependent on gamified contexts as well as employee characteristics (Hamari, Kovisto, \& Sarsa, 2014). Also, one evident problem of attempting to engage individuals while utilising gamification was noted. Research revealed that personalising employee feedback relating to workplace games, was not ideal in respect to transparency and availability. Ideally, to optimise employee engagement, it was thought that workers should be provided with consistent realtime performance statistics, as well as feedback on any developmental needs employees may have. The type of feedback which requires constant monitoring and analysis, which as previously mentioned (on the previous page), requires serious effort which is not without sacrifice (Tansley, Hafermalz, \& Dery, 2016).

As previously mentioned, gamification-related technology and software have been essential for the success of organisations. But it appears that technology and software are deprived of effectiveness, if there are no supportive educational aspects within gamification design. A design or structure that does not just have an overall workplace focus, but conversely an individual consideration of all employees. The problem is preparing, arranging, and designing all-inclusive gamification concerning educational aspects, is "not a stroll in a park" (Sobocinski, 2017). An empirical study must attempt to answer many questions. Questions like, what are the best conditions for motivation-diverse workplaces utilising gamification? 


\subsection{Theme Three: The Ethics Surrounding Gamification can form Barriers to Engagement}

In a world founded on the will to attain morality, managers must ask themselves: are the actions under my supervision based on apt principals like honesty and fairness? When looking at gamification through an ethical lens, many have recommended discovering and addressing the major ethical considerations associated with a gamified workplace. Chief among those considerations is addressing gamification's potential to promote unhealthy gamesmanship, which is correlated with an unproductive workplace (Ruhi, 2015). It appears that ethical concerns are the subsequent result, of the minimal empirical investigation surrounding the moral implications of gamification. The ethical reservations surrounding gamification on a global scale, has even made interested companies including IBM, Coca-Cola, and global software giant SAP, hesitant to implement gamification (Kim \& Werbach, 2016). Based on literature, ethical concerns are currently acting as a barrier for the application of workplace gamification, and is a potential hindrance to employee engagement. The ethics surrounding gamification concern the third theme of this literature review.

Multiple articles have acknowledged a need for ethical behaviour, in order for a gamified workplace to be engaged. The main concern authors recognise, is that workplace gamification could lead to an unhealthy form of gamesmanship (Saunders, 2016). It is easy to see that employees could be so driven by an incentive, whether it be for the use of an "unlockable" privilege or placing first on a leaderboard, that it influences the manipulation of others for individual gain. For instance, a quick examination of organisational community networks can reveal allegations by users of others cheating to increase rankings (McFarlane, 2016). Some research, based on the idea of gamesmanship, even goes to the extent of pointing out that gamification is only ideal on an individual level, counter to situations where employees have to constantly collaborate (Spencer, 2013).

To have a gamified workplace holistically collaborating in a team-oriented fashion, requires deliberation. Considerations which do not promote manipulation, instead conversely counters manipulation. (Kelley \& Johnston, 2012). However, creating such a state of ethical reasoning has been discovered to be difficult in today's age, with employees possessing different value systems (Kang, Edum-Fotwe, Price, \& Thorpe, 2014). Unfortunately, the consciousness of ethical necessities has not led to the development of a robust code for workplace gamification. However, the Engagement Alliance, a non-profit association for gamification practitioners, 
released a "proposed ethics statement" for public comment in late 2012. The three elements within the code were

1. To "help individuals, organisations, and societies achieve their true potential"

2. To "not obfuscate the use of game mechanics with intent to deceive."

3. To "share what I've learned about motivating behaviour with the community" (Zichermann, 2012).

Overall, as a standard for ethically responsible gamification, the proposed code was considered unsatisfactory. At the time of release it was not clear why the Engagement Alliance chose the code's elements, or how the statement as a whole provided valuable direction to practitioners. Such use of terms like "true potential", was considered extremely ambiguous by individuals within the area of gamification. As a result of ambiguity, no gamification-related association has endorsed the statement since its 2012 release (Kim \& Werbach, 2016).

So how can managers approach ethical considerations, which are linked to employee engagement, without a widely accepted protocol? Research has suggested managers or implementers of gamification must act as virtue ethicists, which means participating within workplace gamification itself to communicate a role modelling technique. However, there are complications of a manager acting as a virtue ethicist. For instance, there is no clearly outlined method for involvement (Fröding \& Peterson, 2013).

Research which contributes value in addressing the ethical barriers within gamification, is an ethically encompassing article by Tae Wan Kim and Kevin Werbach. Kim's and Werbach's research acknowledges those who fundamentally challenge the work process like Ian Bogost, who regards the idea of gamification as exploitative (Bogost, 2015). And while exploitation issues are acknowledged, the authors use sources to counter that gamification can be ethical. For example, many have pointed to gamification as a sociological mechanism, which enables workers in the contemporary world to enjoy their occupations due to a more challenging and diverse environment (Burke, 2014). This is in reference to employees worldwide finding their jobs boring, monotonous, and at times meaningless (Harju \& Hakanen, 2016). With attention to the concerns of ethics and counter arguments, Kim and Werbach developed a normatively and descriptively rich framing of ethical issues, to address moral dilemmas associated with gamification. The two authors framing of gamification-related ethical issues, proposed that managers should not: (please turn to next page) 
- Take unfair advantage of workers

- Infringe any involved workers' autonomy

- Intentionally or unintentionally harm workers and other involved parties

- Have a negative effect on the moral character of involved parties (Kim \& Werbach, 2016).

Kims's and Werbach's framing of ethical issues, provides a starting point to approach ethical considerations by outlining actions hypothesised to decrease employee engagement. However, there is no empirical research that follows. Empirical evidence concerning ethics is exactly what is missing in the area of gamification. The type of evidence needed for major corporations (i.e. IBM, Coca-Cola, and SAP) to validate implementing gamification practices. Furthermore, the authors framing of ethical issues does not necessarily clarify what leads to increases in employee engagement. For instance, infringing autonomy is theorised to correlate with low engagement levels, but on the other end of the spectrum it is not completely clear that enabling autonomy would increase engagement levels.

Whether it has been through technology, software, or educational systems, gamification research has been dominated by investigating positive relationships to employee engagement. The ethical concerns surrounding gamification, shed light on the singular aspect which has been theorised to have a negative relationship to engagement. The current research regarding ethics, represents an opportunity to enhance an area lacking empirical evidence. Empirical research relating to how gamification in an ethical capacity positively or negatively impacts employee engagement, will be essential for unique findings. Furthermore, discovering how ethics impact a gamified workplace, could potentially gain insight on how to effectively install gamification. Overall, through a literature review it is clear that there is an absence of thorough ethical analysis, which is in significant contrast to the increasing adoption of gamification across workplaces (Cardador, Northcraft, \& Whicker, 2017). 


\subsection{Theme Four: Player Type Theory}

Much of what has been noted about how individuals facilitate action and interaction within gamified environments, has been derived from knowledge pertaining to economics and broad social dynamics. Player type theory is another form of understanding action and interaction within gamification. Player type theory categorises individuals (e.g. employees) into defined player type groups, based on an individual's preferences or motivations within real-life (e.g. workplaces) and gaming contexts (Kalinauskas, 2014). After years of research (albeit limited), the area of player types has become increasingly defined. The increasing understanding has been theorised to help build effective gamified design, which means player types need to be considered when attempting to install gamification that engages employees. In terms of research, two esteemed figures in reference to gamification, Richard Bartle and Andrzej Marczewski, have established player types as they are known today (Chou, 2016).

Richard Bartle, a British writer and professor at the University of Essex, took an interest in gamification based on his fascination in the design and development of multiplayer, real-time virtual worlds (McCormick, 2013). Bartle's interest in virtual game design and development, eventually led him to consider the question: what do people want out of games? That research question and consequent investigation communicated in a 1996 article, equated to categorising players based on their gaming preference (Bartle, 1996). Based on theoretical groundwork, and qualitative studies Bartle found that there were four aspects individuals typically enjoyed about games. Those four aspects were, achievement within a game context (i.e. completing goals, objectives, checkpoints), exploration within a game (i.e. discovering hidden features), socialising with others (i.e. interaction with players), and lastly imposing upon others (i.e. causing distress) (Bartle, 1996) (Androich, 2011)

Based on findings, Bartle formulated player type theory in a gaming context. Specifically within research, Bartle conceptualised four categories of player types. Those four categories were:

1- Achievers: People who regard, and are subservient to, collecting points and progressing to advanced levels. In reference to exploration, Achievers solely explore to discover new sources of rewards. Achievers in terms of socialising, only really interact if they can utilise communication, to learn about what other players know in terms of the accumulation of points (Androich, 2011) (Chou, 2016). 
2- Explorers- People who enjoy having a game depict its interior mechanisms, or hidden features to them. Explorers overall, seek to find stimulating features and to understand how game aspects function. Explorers, in relation to achievement perceive that scoring points may be critical to progress to the next stage of exploration, but simultaneously believe scoring to be tedious. Socialising for Explorers can be educational as a method of acquiring contemporary ideas to test (Androich, 2011) (Chou, 2016).

3- Socialisers: individuals who are generally interested in people, and what they have to communicate. Cultivating relationships are essential for Socialisers. Such cultivation includes the ability to understand, sympathise, amuse, or even see people develop personally over time. In regard to exploration, Socialisers may perceive exploring as necessary to understand how other players interact. Achieving or accumulating points in a sense could be required to obtain means to interact at higher levels (Androich, 2011) (Chou, 2016).

4- Killers: Individuals who receive utility from imposing themselves on others. Killers imposing others may be perceived as "nice". However, more commonly Killers impose or attack other players with an intent to inflict damage. The greater the distress inflicted, the greater a Killer's satisfaction. Standard point accumulation for Killers is typically vital, in order to become powerful enough to cause disorder. Exploration in a sense is required to find unique and resourceful ways to inflict damage. Furthermore, socialising for a Killer is occasionally useful to, for example, discover other playing habits or to discuss strategies with fellow Killers (Androich, 2011).

Based on the conceptualisation of the four aforementioned player types, Bartle created a test in the year 1999 termed: “The Bartle Test of Gamer Psychology”. Bartle’s test was, and is still, a series of quantitative questions. Bartle's test through analysis and a scoring formula, organises individuals of multiplayer games into the four player type categories (i.e. Achiever, Explorer, Socialiser, Killer) on the basis of motivations (Banerjee \& Das, 2015).

As previously specified, Bartle in 1996 designed and developed his player type theory for a specific community (individuals that play games for fun), in contrast to real-world contexts. Hence, the initial form of player type theory was never meant for understanding workplaces. Bartle even criticised individuals applying his original theory to real-life situations (Castro Soeiro, Santos, \& Alves, 2016). Since Bartle's original work, there has been effort to enhance and adapt the idea of player types (Yee, 2007). However, it was not until 2012 in which a gamification consultant and designer, Andrzej Marczewski, developed player types outside of 
the virtual world. Marcewski's work aimed to relate player types to real-life situations, as a method to develop and enhance gamification knowledge. After consideration of his gamification-related experiences and careful deliberations with others, Marcewski was able to refine player types (Landsell \& Hägglund, 2016). One of the main alterations to player types made was the removal of Killers. Killers within the real-life contexts (i.e. a gamified enterprise) was thought to be a flawed notion. Individuals imposing themselves in environments like workplaces, was considered a non-factor, with there being no significant indication of employees aiming to inflict damage on others for satisfaction (Marczewski, 2016).

Overall Bartle's work, and Marcewski's updated contribution slightly differ, but simultaneously draws common ground with the four most predominant player types within gamification. With the removal of Killers, and a refined/simplified focus on real-life contexts, the four player types as of 2017 are:

Achievers: Individuals deemed as Achievers go to great effort to acquire points and prestige. Achievers favour scenarios in which they're rewarded for completing tasks. Earning the recognition of others through such elements as public leaderboards is important to Achievers (Chou, 2016).

Free Spirits: Free Spirits do not desire to be restricted in how they work. Associated with creativity, Free Spirits are likely to create the most personal content. Free Spirits wish to gain rewards that represent self-expression, customisation, and autonomy (Chou, 2016).

Philanthropists: This player type desires to give back to others. Philanthropists have selflessness for others and are driven by an organisational purpose. Motivation for Philanthropists primarily comes from being able to elevate others and feeling fulfilment (Chou, 2016).

$\underline{\text { Socialisers: }}$ This player type desires interaction with others. Socialisers are interested in parts of the workplace that enable them to accomplish this, and will promote internal social networks. A reward that commonly influences Socialisers in workplaces, is the privilege of attending a networking event (e.g. conference). Socialisers' motivation comes from the social linking aspects of relatedness (Chou, 2016).

How player types are known today provides managers working with gamification, a simple framework to deliberate about the types of individuals they may currently have, or prospective individuals that could best fit a workplace. For example, if in a gamified context there is a 
dominant Free Spirit presence, then rewards that express a sense of freedom would be appropriate based on player type theory.

The aforementioned player types are thought to assist with creating the best gamification structure. However, a manager may need to rigorously assess a workplace to understand the existing player types within a workplace. Furthermore, there is no form of recognised assessment for acquiring understanding, in terms of an updated "Bartle Test" (Barr, 2017). Thoroughly examining the research conducted for this thesis, may provide a technique to assess and ultimately understand the impact of player types within workplaces. Recognising player types within research could potentially provide a basis to comprehend how different motivations impact engagement, therefore how gamification can be successfully managed within workplaces. Presently however, in the words of Andrzej Marczewski, player types can assist a general "plan in how to motivate/engage" employees (Marczewski, 2013). 
2.6 Additional Literature: Factors that Result in Gamification being Perceived as an Employee Engagement Tool, which Produces both Faith and Scepticism

Gamification over the past five years has been proclaimed as something that can, if done right, change the future of workplaces globally (Mack, 2014). The proclaimed benefits of increased productivity and employee devotion supplement this claim. However, despite its publicised benefits, little empirical research has been completed investigating factors that determine the success or failure of organisational gamification initiatives (Ruhi, 2015). A framing of issues based on a review of theoretical information, like Jung Tae Kim's and Won-Hyung Lee's 2015 article (referred to on pages 22-23), can only be taken practically so far without real-world testing and results (Kim \& Lee, 2015). There is additional literature delving into aspects of gamification, which did not fall into the four previously outlined themes. The additional literature surrounding gamification as an employee engagement tool, primarily creates both faith and scepticism in gamification as a viable work process. The coinciding faith and scepticism may explain why gamification is cited as a future utility, and why gamification despite its prophecy, has not been widely implemented (Caul \& Roberts, 2015).

As William Gibson, a famous author said: “The future is already here; it's just not yet evenly distributed" (Chamorro-Premuzic \& et al). Although gamification is presently being utilised in some workplaces around the globe, gamification in most circumstances is far from the norm (Nuki, 2016). However, it seems that the workplaces incorporating gamification across the world, widely perceive that the work process is beneficial in terms of generational and industry alignment, connection, and measurement.

There is a perception held by some that gamification aligns with today's younger generations, specifically Millennials (born between 1986 and 1995) and Generation Y (born after 1996) (Jacobs, 2016). The theoretical approaches of two Americans, Neil Howe and William Strauss, fit well into the idea of gamification aligning with younger individuals. Howe and Strauss assert that the outlook of younger generations has been significantly impacted by the rapid development and over exposure to technology. Ultimately, a multitude of researchers' perceive that the over exposure to technology, has promoted a creative and competitive workplace and a desire for small rewards as incentives for achievements, factors closely associated with gamification (Werbach \& Hunter, 2015) (Bergen \& Bressler, 2011). The perceived alignment of gamification and younger generations, has consequently inspired some workplaces to transition into a more gamified environment. The idea behind the transition, is that gamification 
could increase the engagement of workers who are both early in their careers (i.e. Millennials), and who are close to pursuing full-time employment (i.e. Generation Y) (Vinichenko, Melnichuk, Kirillov, Makushkin, \& Melnichuk, 2016).

In addition to generational alignment, the concepts, tools, and evaluation techniques surrounding gamification have been strongly interlinked with the technology industry (Silverman, 2011). For instance, the tech industry is thought to be synonymous with a culture of extreme innovation, change, and differentiation. Qualities which researchers think strongly correlate with the successful implementation of gamification. Due to the nature of gamification, some research has indicated that employees in a technology environment, would be more adaptable and successful with gamified practices in relation to other industries (Caul \& Roberts, 2015) (Disys, 2017).

An additional reason why some organisations are implementing gamification, is the modern state of "hyper-connection". Hyper-connection is the ability to interact with others through communication systems, which have become more pervasive and ever-present with high recording/processing ability. For instance, communicating via hand-written letters has been replaced by email, wireless handheld devices, and organisational intranets. Hyper-connection has enabled organisations to keep employees up-to-date with ease, giving companies the ability to engage employees in real-time with gamified results (Gibson \& Sodeman, 2014). Some organisations see hyper-connection as a chance to engage employees on a 24/7 basis (Purcell $\&$ Lee, 2014). Furthermore, the opportunity for hyper-connection also relates to gamification's entrenchment with analytics. The analytical information that can be generated through gamified technology and software, enables unprecedented amounts of data evaluation in ways organisations perceive as advantageous. Beneficial to the point in which companies have more potential to adopt gamification practices, in an attempt to harness and discover data (Harbert, 2014). The type of data that facilities human evaluation, in which organisations may use in programs (e.g. Deloitte's "pick a path" interactive program for graduates- referenced on page 16) (Rapt, 2017).

Even with aspects of workplace gamification being considered advantageous for productivity, there are reasons why the work process has not been widely implemented. Firstly, as previously mentioned in the third theme of this literature review, organisations have their ethical reservations (Kim \& Werbach, 2016). Secondly, and maybe more importantly, there is an overall lack of empirical data relating to gamification. Not only has there been little ethical 
analysis of gamification (mentioned throughout Theme Three), but a minimal amount of empirical research examining gamification's impact overall. Data that influences and validates an organisational decision to implement gamification. To compound organisational scepticism, the lack of empirical evidence has even led to some researchers communicating that workplaces should avoid "jumping on the gamification bandwagon" carelessly (Ruhi, 2015). It seems that a lack of empirical study, has in part led to a lack of workplace gamification.

Before concluding non-thematic literature, there needs to be an emphasis on workplace gamification techniques (which have briefly been mentioned throughout this literature review). Workplace gamification techniques, are methods of influencing behaviour (Bowman, 2014). Across literature, the four most common gamified techniques in the workplace are

- Customisation- an ability to modify workplace surroundings and virtual aspects (i.e. virtual avatars and workplace screensavers) (Coppens, 2014).

- Intangible privileges- the ability to create and adapt work duties (Cheong, Filippou, \& Cheong, 2014).

- Leaderboards- physical or virtual boards that communicate the point totals of employees in relation to gamified work (Sarangi \& Shah, 2015).

- Physical rewards- compensation commonly in the form of gifts and vouchers (Sarangi \& Shah, 2015).

Ultimately the four aforementioned gamification techniques, provide ways in which managers can influence employees. Furthermore, gamification techniques provide the opportunity to comply with certain player types e.g. a manager utilising a workplace leaderboard would provide Achievers with the opportunity to acquire prestige (through recognition) amongst colleagues.

Additional literature that does not fall within the four previously outlined themes, sheds light on important information. Information which suggests additional empirical study is essential for the implementation of workplace gamification. Additionally, important information within non-thematic literature generates interesting questions. Questions like: is gamification positively aligned with younger generations and the technology industry? Such alignment may be useful to understand the engagement levels and installation of gamification within work sectors. 


\subsection{A Brief Summation of Chapter Two}

Chapter Two has attempted to deliver an overview of the theory and research literature, associated with gamification in relation to employee engagement. By analysing content through a search methodology, it was decided that literature would be written thematically.

Gamification's integration of technology and software to foster engagement, brought forth key information to light. A research contribution by Marianna Sigala in 2015, initiated a more concentrated focus on technology and software relating to gamification. The positive business impact of gamification found within research, resulted in the questioning of how gamification impacts in the area of employee engagement. Sigala's findings and increased publicity around gamified technology and software, subsequently inspired research. Research such as a 2016 study conducted by Andy Campbell, which discovered that Oracle's implementation of gamification led to higher engagement levels. Even more recently, gamified technology and software, was again found to increase employee engagement, specifically at Electronic Arts and Deloitte.

Theme two, gamification's deployment of educational aspects to foster engagement, delivered critical insight into the ways employees learn through gamification. Fundamentally, the application of gamification was discovered to have progressed from rational economic ideologies to behavioural ideologies. The ideological development ultimately communicated the importance of individual employee consideration. To further educational gamification research, Jung Tae Kim's and Won-Hyung Lee's 2015 work, identified gamification's four primary educational characteristics (curiosity, challenge, fantasy, and control). Ultimately, Lee's and Kim's work concludes that gamification's educational characteristics, make gamified learning superior to traditional learning methods. Additionally, in another study, gamification and its educational characteristics were found to enable individuals to become more adept in terms of innovation, being responsive in uncertain environments, and thriving in conditions of recurrent change.

Theme three brought attention to something that could hinder gamified engagement, ethical concerns. The main ethical concern of gamified workplaces, is the theoretical and practical evidence of gamification promoting unhealthy gamesmanship. The type of gamesmanship that negatively impacts employee engagement. Even with great concern, worry has not equated to an effective ethical code. To address ethical concerns, research has suggested managers must act as virtue ethicists. However, there is no clearly outlined method for a manager to effectively 
act as a virtue ethicist. In terms of ethical guidance, Tae Wan Kim's and Kevin Werbach's research in 2016, provides advice on what a manager should not do in reference to handling employees. However, Kim's and Werbach's research is not validated by empirical study, and does not clarify what actions managers can execute to increase employee engagement.

Player type theory concerns theme four of the literature review. Player type theory categorises individuals into defined player type groups, based on individual preferences or motivations. Richard Bartle published player type theory in 1996 in relation to gaming contexts. Bartle conceptualised four categories of player types which were Achievers (motivated by progression), Explorers (driven by discovery), Socialisers (inspired by interaction), and Killers (interested in executing imposition). In 2012, Andrzej Marczewski framed player types ranging beyond virtual worlds. A primary alteration to player types was the removal of Killers, based on there being little evidence of purposefully imposing individuals. Overall, Bartle's work and Marcewski's updated contribution slightly differs, but there is common ground regarding the four predominant player types within gamification. The four predominant player types are Achievers (driven by points and prestige), Free Spirits (inspired by self-expression, customisation, and autonomy), Philanthropists (motivated by elevating others), and Socialisers (enthused by interaction).

Additional notes, outside the four aforementioned themes, produces both faith and scepticism in gamification as a work process. Some organisations have faith and have utilised workplace gamification, due to theoretical indications that the work process aligns closely with younger generations (i.e. Millennials and Generation Y) and the technology industry. An additional reason why some organisations are implementing gamification, is the modern state of communication systems. Some organisations see increased communication as a chance to engage employees with gamification on a frequent basis. The analytical information that can be generated through gamified technology and software, is another reason why organisations are utilising gamification. However, there are reasons why the work process has not been widely practised. Firstly, organisations have ethical reservations. Secondly, there is an overall lack of empirical data relating to gamification. A lack of empirical evidence which influences and validates an organisational decision to implement gamification. Before concluding nonthematic literature, workplace gamification techniques were highlighted. Workplace gamification techniques are methods of influencing behaviour. The four common gamified techniques in workplaces are customisation, intangible privileges, leaderboards, and physical rewards. 
The information noted in Chapter Two indicated many questions that must be investigated, pertaining to the two research questions in this thesis. Questions such as:

- How does gamified technology and software impact employee engagement in a New Zealand context?

- What are the best conditions for motivation-diverse workplaces utilising gamification?

- What ethical actions increase employee engagement?

- How do player types impact employee engagement?

- Is gamification positively aligned with younger generations and the technology industry? 


\section{Chapter Three: Methodology}

Chapter Three is all about the description of research that has been conducted for this thesis. Based on how research unfolded, description will include information about research design, data collection, and data analysis procedures. Description will also include discussion on the suitability of procedures, pertaining to the two formulated research questions. Not only will practical procedures be presented in Chapter Three, but theoretical notions also.

\subsection{Introductory Notes and a Brief Look Back at the Research Questions}

The overall methodological philosophy, approach, and procedures utilised in this thesis, were intended to all connect in order to complement each other. A linked approach was desired to direct an overall orientation for research. Not having a clear linkage and direction was perceived to make work unnecessarily difficult in terms of interpretation.

Ultimately, theses can be based on either qualitative or quantitative data, or even centred on a combination of both. For some academics, the type of research that is conducted depends on the preferences and abilities of the researcher(s) (Hughes, 2016). However, the type of research conducted for this thesis is primarily based on the information desired. Therefore, it was important to conduct an approach revolving around the two research questions in this thesis. As stated in "Chapter One: Overview", the two research questions are

\section{How does gamification impact employee engagement in New Zealand?}

\section{How can gamification be successfully installed within New Zealand workplaces?}

It is important to conduct research based on the two research questions above for three reasons. Firstly, pertaining to the first research question, exploration will be significant as investigating gamification's impact within New Zealand could provide insight on how to improve the state of employee engagement. Information could potentially act as a catalyst for managers implementing gamification into action. Additionally, findings pertaining to both research questions could communicate strong relationships concerning implementing and managing gamification. Relationships could result in a framework or guide to help workplaces successfully handle, and reap the rewards from workplace gamification. The third potential benefit of investigating the research questions is that findings could assist in validating, contradicting, or extending the positions within gamification research. 


\subsection{Research Philosophy: What Research Paradigm is Appropriate?}

In order to justify and ultimately conduct and evaluate research, it is essential to acknowledge the importance of the assumptions that can come from research. Assumptions can be gained from a research paradigm, a set of basic philosophical principals which determines how we understand the world, and the nature of knowledge. Furthermore, a paradigm is essentially a person's beliefs and opinions, it cannot be found to be either true or false (Guba \& Lincoln, 1994). Therefore, a paradigm sets an orientation for a researcher which is reflected throughout an entire research design. There are two frequently mentioned categories concerning paradigms: positivism and interpretive (Chua, 1986) (DeLuca, Gallivan, \& Kock, 2008).

Over the many decades of academic investigation, management research has been dominated by the positivist assumption that there is only one real-world and that true, objective, and universal knowledge is possible (Brand, 2009). Furthermore, this positivist view and the assumptions that come from the perspective has been critiqued. A difference of opinion or belief has generated alternative interpretive positions. Moreover, the interpretive paradigm has presented fundamentally differing views from the positivist, where there is no such thing as objective knowledge, only subjective knowledge. For instance, individuals can perceive reality in different ways, where knowledge can be considered as both socially constructed through interactions between individuals, and influenced by overall cultural, political, and gender values. For example, in a gamification research context, opinions can vary based on social constructions like workplace surroundings and the level of largely inherent values like competitiveness.

Ultimately, based on a careful consideration the interpretive paradigm was selected to guide research. The selection of the paradigm was due to the assumption that access to the reality of research findings (given or socially constructed), could be primarily found through subjective social constructions such as shared meanings, consciousness and language (van der MeerKooistra \& Vosselman, 2012). 


\subsection{Research Approach: Qualitative, Quantitative, or both?}

Using a qualitative, quantitative or a mixed-method approach, was decided upon after selecting the interpretive paradigm to direct research. To select an approach, the two aforementioned research questions and topic of this thesis were scrutinised. After inspection, the two research questions and the topic of workplace gamification itself, were deemed to be exploratory by nature. Exploratory in the sense that there is still plenty of empirical evidence needed to fully understand gamification, and the corresponding impact on employee engagement the work process has. Overall, on the basis of the literature review in Chapter Two, it was determined that there was much more understanding needed to justify descriptive research techniques (i.e. quantitative research practices like surveys). There was a general lack of conceptual distinctions and minimal explanatory relationships (i.e. a deficiency of frameworks), relating to gamification within workplaces.

Overall, the exploratory nature of this thesis entailed the need for exploratory research. Exploratory research concerns investigation with an emphasis on obtaining ideas and insights about a broad problem (i.e. the impact of gamification on employee engagement), so that problem can be broken into smaller sub-problems. The lack of quantifiable detail needed for gaining ideas about a broad problem, resulted in the use of qualitative techniques (Laczniak, 2004). Additionally, qualitative techniques were considered appropriate to acquire data on social constructions such as shared meanings, consciousness and language. Constructs in which the interpretive paradigm coincides with (van der Meer-Kooistra \& Vosselman, 2012). 


\subsection{Initiating the Research Design: Choosing a Technique for Data Collection}

After selecting a research philosophy and approach, multiple steps of research action were implemented. However, before action was executed there was a decision made on how data was going to be obtained. In-depth one-to-one interviews were chosen as the technique to collect data. The reasoning behind selecting one-to-one in-depth interviews, was due to the technique's appropriate exploration of views, experiences, and motivations in relation to the thesis topic. For example, the one-to-one isolation of interview participants was preferable. Topics such as personal productivity and ethical factors within gamification, were considered personal and sensitive issues that needed to be processed on an individual level. It was deemed more likely that an interviewee would communicate any potentially sensitive dialogue (i.e. unethical acts occurring within a gamified workplace), if they knew there was only one other person in conversation. An overcrowding of participants within alternative qualitative techniques such as the conduction of focus groups, may have intimidated an interviewee. Intimidation could have been the result of participants using defensive strategies or tactics, in order to guard themselves against the anxiety of being judged, which has proven to be common in focus groups (Acocella, 2012).

The in-depth one-to-one interview technique was in conjunction with the philosophical base of interpretive research, phenomenology. Specifically, transcendental phenomenology, which aims to discover individuals (e.g. New Zealand employees) experiences of a concept or phenomenon (i.e. gamification in a workplace) (Boland, 1985). Interpretive transcendental phenomenology research, is appropriate as exploring the effect, essence, and nature of gamification, focuses on the holistic complexity of human sense-making (Kaplan \& Maxwell, 1994).

After determining the research philosophy, approach, and technique, multiple aspects of action were implemented. In total, five methodological aspects were executed which were:

- Bracketing

- Creating the interview schedule

- Recruitment of participants

- Conducting the interviews

- Analysing the obtained data 


\subsubsection{Bracketing}

Before creating an interview schedule, recruiting, conducting interviews, and data analysis, it was acknowledged that some resemblance of reflexivity was desired throughout research. Reflexivity is simply an ability to evaluate oneself. A need for evaluation in research is important for reflecting on biases and preconceptions, so that a researcher does not end up with unfitting data (Nadin \& Cassell, 2006). To ensure there was no unfairness in research, "bracketing" (also referred to as epoché), an act in the philosophical movement of phenomenology, was utilised. Whereas reflexivity is an ability to evaluate oneself, bracketing is the actual process of suspending judgment about the natural world to focus on the analysis of experience. Bracketing can be understood as the "unpacking" of phenomena, or the methodical shedding of biases until only a research experience remains (Fay \& Riot, 2007).

The process of bracketing was executed in three ways

\section{Dialogue}

Dialogue or interaction took place before and after research action initiated. Dialogue occurred within meetings and at a series of postgraduate forums at Victoria University of Wellington (VUW) (Morgan, 2011). Dialogue concerned aspects of current gamification knowledge and content relating to previous experiences with qualitative research. Key points from dialogue were noted, which meant the dialogue had been "bracketed". Key points included ideas related to gamification and the incorporation of literature within empirical study (Fay \& Riot, 2007).

\section{Recording Notes Throughout the Research Process}

Recording memos took place during, data collection, analysis, and when writing about findings (Morgan, 2011). The memos were noted when there was a sense of bias or preconceived notion. Having a record of potential biases, knowledge, and preconceived notions helped with the research process. For instance, being able to recount themes of potential partiality throughout investigation, indicated periods where it was necessary to step back and reprogram the mind. 
3. Writing a Final Report

A final report containing biases, preconceived notions, and knowledge was published for research use. Overall the report enabled the awareness of the potential biases within research, through the recount of results and interpretations (Morgan, 2011). Being able to reprogram and recognise biases enabled a sense of suspending judgment about the natural world, to instead focus on an analysis of experience. This sense helped contribute to a judgement on the validity of findings (Fay \& Riot, 2007). 


\subsubsection{Creation of the Interview Schedule}

Suitable exploration of views, experiences, and motivations of individuals relating to the two research questions, required more detail than a simple "yes" or "no" answer. Therefore, in order to capture knowledge of interviewee experiences with gamification, an in-depth interview guideline was developed based on open-ended questions, as opposed to close-ended queries. Open-ended questions were utilised to allow participants to talk freely without being constrained in interviews. Participants being able to talk freely enabled more exploratory depth, for a thesis based on exploratory elements (as mentioned in Section 3.3).

The literature review conducted in Chapter Two, was analysed to validate and inform in-depth interviews. As a result, the formulation of an open-ended interview guide was based on the content found in the review (i.e. gamified technology and software, educational aspects, ethics, player types, and additional literature). In total, ten open-ended questions were formulated based on literature findings. The reliance on ten key questions, was thought to provide the ability to additionally probe or ask follow up questions dependent on interviewees, as ten questions places little restriction on time. Ultimately, the reliance of ten questions supplemented with the ability to probe, equated to a semi-structured interview guide. The flexibility of the semi-structured approach, particularly when compared to completely structured interviews, was thought to positively influence the discovery and elaboration of information.

To ensure the guide was effective for in-depth interviews, interview guide questions were discussed with university colleagues with research experience. Colleagues provided validation of question selection, and provided important tips pertaining to tone of voice and body language. Interview guide questions were also tested with individuals who had previous experience with gamification. The primary goals of testing was to ensure that interview questions were easy to understand, and that questions would lead to satisfactory knowledge relating to thesis objectives. During the tests notes were taken. After analysing notes, there were small modifications made to the interview guide. Based on analysis, there was a rewording of three questions to ensure that future interviewees would have greater understanding. (To see the interview guide used within the research process, please refer to Appendix One.) 


\subsubsection{Recruitment}

The process by which individuals were recruited as potential subjects in the research study, was a carefully deliberated process. To initiate the process of recruitment a sampling technique was first considered. After consideration, it was decided that purposive sampling (also known as selective sampling) would be utilised in the study. Purposive sampling occurs when a researcher relies on their own judgment, when selecting individuals of a population to participate in research (Research Methodology, 2017) (Etikan, Musa, \& Alkassim, 2015). Purposive sampling was utilised, as the sample of participants were thoughtfully and purposefully recruited. The goal of selecting participants was to focus on particular characteristics of a population, which were thought to best enable findings in relation to the two research questions in this thesis.

Based on dialogue communication pertaining to recruitment, it was thought to be best via email. Dialogue and reflection led to the creation of a procedural email sent through social media outlets targeting the Wellington Region, and organisational emails across the Wellington Region. The email contained research information and aimed to get permission to interact with interviewees (please see Appendix Two: Email to Prospective Interviewees). Within an email, there was a pre-survey concerning gamification and its meaning, and questions regarding industries worked in, age, characteristics and the will to be interviewed. Overall, the email was intended to gain information on whether prospective participants met three purposive ideals. Those three ideals were:

- Participants that were employees in an environment working under managers. Employees working under managers were ideal in order to acquire direct personal insight, into the perspective of employees and their engagement levels.

- Participants who had, or currently were, being exposed to some form of gamification in the workplace. Having participants who had experience being exposed to gamification was ideal, as the experience provided a basis to gain desired research information (i.e. the impact of gamification).

- Participants that were from or working in the Wellington Region. Ensuring participants were from a specific area where the primary investigator was from, ensured that investigation wouldn't undergo certain difficulties. Difficulties like traveling distances with inadequate funds, and having to travel distances which would have placed an increased time restriction on the interpretation of information. 
Additionally, the email aimed to find out which possible player type categories prospective interviewees represented. This was simply done by incorporating one question which allowed participants to acknowledge their individual characteristics.

There were twenty ideal prospective interviewees who granted interview permission. However, to attain just any interviewee who met the purposive ideals outlined, was not considered optimal. After reviewing potential participants, selection of interviewees was made based on diversity. Diversity was considered on the basis of two factors, age and industries worked in. Firstly, there was a will to obtain a sample across a multitude of generations. The desire to interview individuals from different time periods, was due to literature findings which stated gamification aligns with younger generations (Werbach \& Hunter, 2015) (Bergen \& Bressler, 2011). The desire to know what industries potential interviewees worked in, was due research findings which strongly interlinked gamification with the technology industry (Silverman, 2011) (Caul \& Roberts, 2015) (Disys, 2017). Having knowledge of age and industries, was thought to enable the contrasting of both generations and industries in relation to gamificationrelated employee engagement. Potentially discovering if gamification aligns with specific generations or industries, was thought of as a way to possibly validate, contradict, or extend theory in relation to thesis objectives.

In reference to the number of participants that were to undergo one-to-one interviews, the number of interviewees' chosen was twelve. The decision regarding the amount of interviewees was made based on two categories of advice. Firstly, the interviewee amount was based on the process of bracketing. Dialogue, part of the process of bracketing, enabled communication with researchers who had valuable experience conducting theses. Researchers advised that ten to fifteen participants were appropriate for data collection. Following advice from researchers, there was an investigation of published academic research. Research which provided guidelines for effective qualitative sampling. A review of research indicated that there needed to be enough participants, in which additional interviewees wouldn't provide any additional insights, a situation referred to as "saturation". Saturation is reached when learning is, or is near, to nonexistent from each succeeding interview (Boddy, 2016). Overall, research indicated that ten to fifteen interviewees were again an appropriate amount for a Master's thesis. Ultimately, the amount of participants decided to undergo one-to-one interviews, was twelve. Twelve seemed like a manageable total which represented a number that was advised. Of course, conducting fifteen interviews was an option. However, twelve was thought to be ideal in terms of reaching saturation and having enough time to conduct and analyse interviews in a rigorous fashion. 


\subsubsection{Conducting the Interviews}

Before twelve in-depth interviews took place, participants were provided with information about the objectives of research. The goal of providing information was to ensure interviewees had adequate knowledge of the study (Please see Appendix Three: Information Sheet). The creation and presentation of consent forms was also executed (please see Appendix Four:

\section{Consent Form).}

In-depth interviews occurred in-person within employee homes and public spaces around the Wellington Region. During interviews, participants were given a chance to clarify any uncertainties (i.e. objectives of the study). After clarification, a recording device was used to obtain an account of interviewee interaction. Subsequently, there was researcher questioning of interviewees with the guideline of ten open-ended questions, formulated based on literature findings. Ten proved to be a suitable number, as it allowed room to explore desired themes, while additionally leaving enough time to ask suitable follow-up or probing questions dependent on interview content. Probing questions were essential, as at times there was not a complete understanding of a response, or when answers were vague there was a desire to obtain more specific or in-depth information. The flexibility of a semi-structured approach, particularly compared to structured interviews, enabled the discovery and elaboration of information that was important for research, which wasn't necessarily thought of as initially pertinent. 


\subsubsection{Data Analysis}

To analyse data obtained, firstly interviews were transcribed word for word via the recording device used for interviews. Transcription data was saved in multiple Microsoft Word documents.

After transcription, many different methods of analysis in qualitative research were considered (template, discourse, narrative analysis etc.). The method to analyse the recordings was chosen to be template analysis. Template analysis was deemed to be the most appropriate, as the analysis helped thematically analyse the qualitative data. The thematic organisation was especially helpful, as information obtained developed a coding template summarising themes identified in the literature review and new themes communicated through interviews. Template analysis effectively organised themes in a meaningful manner (Brooks, McCluskey, Turley, \& King, 2015). Template analysis was utilised by:

- Initially using a priori codes, which identified themes strongly expected to be relevant to research (i.e. gamified technology and software, educational aspects, ethics, player types, additional literature)

- Secondly, analysis identified segments that corresponded to a priori themes which were coded as such. Otherwise, new themes were identified to include relevant material subsequently evading thematic bias, and structured into a template. New themes within template analysis included the impact of management actions, the recognition of gamification techniques, and employees psychological needs

- Ultimately, template analysis resulted in a hierarchical listing of themes within a template (to see the final hierarchical listing of themes used within template analysis, please refer to Appendix Five: Template Hierarchy)

Quotes associated with themes were placed in Word documents. Such allocation reduced the qualitative data which was determined to be unstructured text into themes which were relevant for evaluation. Additionally quotes were segmented to compare the perspectives of different interviewee groups (i.e. player types, younger generations, older generations, work fields).

Ultimately, template analysis structured data into themes strongly relating to research objectives. Template analysis was also seen as a technique which enabled the discovery of explanatory relationships. 


\subsection{Ethical Considerations}

Ethics are recognised beliefs or principals that dictate behaviour (Oxford Dictionary, 2017). Ethics importance in relation to research is significant, as ethics can dictate aims of investigation, error rates, and overall information. The importance of ethics has created ethical norms within research (Walton, 2017).

Luckily with this thesis being completed at VUW, there were proven and thorough ethical procedures in place. Ethical standards were a prerequisite with research having to be in conjunction with VUW's, Pipitea Ethics Committee values. The process of submitting material for committee approval (i.e. information sheets, consent forms, and general research objectives) helped validate and inform an ethical standard. VUW's ethical procedures emphasised the respect and care for individuals, social and cultural contexts, the environment, and an overall avoidance of conflicting interest (Victoria University of Wellington, 2017). 


\subsection{Concluding Chapter Three}

Chapter Three provided a description of the research conducted for this thesis. Description included the use of a research philosophy (interpretivism), approach (qualitative), and a technique (one-to-one in-depth interviews). Additionally, description included a strategy pertaining to recruitment, knowledge of how interviews were conducted, and how qualitative data was analysed. The overall hope with Chapter Three, was that all aspects of methodology linked together to direct an overall orientation for quality research.

Overall, the process of using the methodology gave way to many lessons about research. The most important lesson of all is that research cannot be perfect. For instance, purposive sampling has its limitations (elaborated on in Chapter Six: Limitations of research). However, research isn't supposed to be perfect, it is meant to be a systematic study of sources, acting as a catalyst to learning about a concept and establishing conclusions (Merriam Webster, 2017) (Kinash, 2017). 


\section{Chapter Four: Findings and Analysis}

Chapter Four outlines the findings of the thesis study, and also the discussion or analysis of those findings. The fourth chapter will be communicated in the form of written text and illustrations, in relation to the two research questions presented in this thesis.

\subsection{Framing the Interviewees}

"Figure Three: Findings Table" below, presents a summary that visualises a multitude of categories, specifically four, that correspond with individual interviewees that participated in the research study.

Figure Three: Findings Table

\begin{tabular}{|l|l|l|l|}
\hline \multicolumn{4}{|c|}{ Findings Table } \\
\hline Interviewee \# & Generation & Industry & Player Type \\
\hline Interviewee One & Generation Z & Catering & Philanthropist \\
\hline Interviewee Two & Millennial & Retail & Socialiser \\
\hline Interviewee Three & Baby Boomer & Property & Achiever \\
\hline Interviewee Four & Baby Boomer & Finance & Achiever \\
\hline Interviewee Five & Millennial & Design & Achiever \\
\hline Interviewee Six & Baby Boomer & Education & Philanthropist \\
\hline Interviewee Seven & Millennial & Technology & Free Spirit \\
\hline Interviewee Eight & Baby Boomer & Technology & Philanthropist \\
\hline Interviewee Nine & Millennial & Technology & Achiever \\
\hline Interviewee Ten & Generation X & Health & Philanthropist \\
\hline Interviewee Eleven & Millennial & Education & Socialiser \\
\hline Interviewee Twelve & Generation Z & Retail & Free Spirit \\
\hline
\end{tabular}


"Generation" indicates what time period interviewees were born in. For example, some interviewees in the study were "Baby Boomers" as they were born following World War II, from 1946 to 1964. In total, interviewees spanned across four generations: Baby Boomers, Generation X (born 1965 to 1976), Millennials (1977 to 1995), and Generation Z (1996 and later) (Bump, 2017) (The Center for Generational Kinetics, 2017). Distinguishing generations was considered worthwhile, as reputable literature found that different age groups or generations may differ in terms of the engagement gained from gamification. (Werbach \& Hunter, 2015) (Baptista \& Oliveira, 2017). Having a note of generational differences enables knowledge pertaining to how generations differ in terms of gamification-related engagement. "Industry" communicates a work or enterprise field interviewees operated in while experiencing some form of gamification. Interviewees in the study varied in terms of work. Employees worked across a total of eight work industries, which ranged from catering to education for reference. Distinguishing which industry individuals worked in was important, as employees working at companies more adept with technology was thought to align better with gamification (Campbell, 2016) (Caul \& Roberts, 2015) (Disys, 2017). Taking note of "Industry" enables a perspective of how gamification impacts certain work sectors.

The third category "Player Type", directly relates to research analysis and judgement of each interviewee's player type. Identifying player types was largely interpreted through an examination of interview transcripts, which contained information relating to traits within player type research. Separating and identifying player types was considered to be of importance, as understanding player types could gain information on how a multitude of personalities co-exist in a gamified workplace. The type of understanding that could assist a manager with installing gamification, pertaining to the second research question concerning this thesis.

Overall, Figure Three communicates that there were two interviewees from Generation Z, five Millennials, one from Generation X, and four Baby Boomers. Interviewees spanned across 8 work or enterprise fields. Work fields with multiple interviewees concerned the technology (three interviewees), retail (two interviewees), and education sectors (two interviewees). Based on qualitative analysis, it was determined that there were four Achievers, two Free Spirits, four Philanthropists, and two Socialisers. 


\subsection{Preliminary Notes}

Before delving into qualitative findings, there should be a further recognition of the two queries which dictated investigation. The two research questions concerning this thesis are:

\section{How does gamification impact employee engagement in New Zealand?}

\section{How can gamification be successfully installed within New Zealand workplaces?}

As seen above, the two research questions predominately deal with three topics of interest being gamification, gamified employee engagement, and the management of gamification. Based on the topics of this thesis and subsequent qualitative analysis, findings concerned:

- The impact of management actions within gamification

- How different gamification applications impacted employee engagement

- Interviewees and their player types

- Gamification and its alignment with generations and work fields 


\subsection{The Impact of Management Actions within Gamification}

In interviews, there was one key trend which all participants communicated. New Zealand participants communicated the importance of managerial actions within gamification, which partly dictated employee engagement in workplaces. Specific managerial actions corresponded to increases in employee engagement. Simultaneously, alternative managerial actions correlated with decreases employee engagement. "Quote One” said by Interviewee Two below, was one of the first quotes which indicated the impact management has on gamification.

\section{Quote One: “A slack manager upsets all. A manager who doesn't acknowledge hard work by employees means less enthusiasm. A slack manager in work games means fewer opportunities to increase my capabilities” (Interviewee Two)}

Of course effective management is generally a prerequisite for a highly engaged workforce (Whittington \& Galpin, 2010). But the management of gamification, unlike most work processes, was found to deal with two sensitive issues at extreme levels (gamesmanship and fairness). Levels where employees absolutely needed to trust the ability of management.

Interviewees communicated three aspects (gamesmanship, clarity, autonomy) which impacted the effectiveness of management. For instance, the ability of a manager handling gamesmanship was at the core of discussion. If New Zealand interviewees' perceived management could cope with the potential for unfair gamesmanship, employees were significantly more inclined to engage at higher levels. Participants needed to know management could act as an authoritative figure, to punish any foul play within a gamified environment. Additionally, interviewees needed to know management could effectively monitor a gamified workplace, to ensure no manipulation was occurring. No manipulation happening meant employees were in a desirable work environment which promoted fairness. "Quote Two" communicated by Interviewee One below, represents the positive impact of a manager being able to control gamesmanship.

Quote Two: "It needs to be a fair environment. It's pretty valuable for a manager not to be a pushover, it's the whole point of being a manager. You manage and monitor. I think my respect would lead to being more inclined to work" (Interviewee One) 
Conversely, interviewees desire to work towards a gamified incentive significantly declined if their efforts had the potential to be foiled. Participants were unmotivated, or dis-engaged by the possibility of co-workers having the ability to "game" or "cheat the system". "Quote Three" said by Interviewee Three, accurately reflects interviewee feelings on the poor management of gamesmanship in relation to their work engagement.

\section{Quote Three: "If there is inappropriate cheating and a manager wasn't doing their job well in terms of taking care of it, I would have to report it. It just wouldn't be a fair in the bigger picture. I would be less likely to work for them" (Interviewee Three)}

Ultimately, interviewees communicated the desire for a gamified environment, where management could ensure all employees had a fair opportunity to be rewarded. An unfair or cheating environment where a manager had a lack of ability or control, was worrisome as gamification rewards can have an impact on employee happiness and perceptions of fairness.

Another aspect that impacted engagement was the clarity of gamification. Clarity of gamified rules and purpose dictated by management. When interviewees knew the rules and purpose of gamification within workplaces, they felt like essential elements of a workplace's mission. Simple things like having management install a noticeboard comprising of gamification rules, and employees being able to receive a top-down explanation on why gamification was in place, was a catalyst to employees being productive and enjoying work. "Quote Four" and "Quote Five" describe the positive impact of gamification clarity in the workplace.

\section{Quote Four: "I would be more inclined to work if managers were interactive with me. If a manager is approachable in terms of rules that would make me work" (Interviewee Nine)}

Quote Five: "It (clarity) would help me. Help me with learning processes and overall support. That type of support would increase my will to work", (Interviewee Ten) 
Conversely, if interviewees did not perceive clarity in reference to workplace gamification, productivity levels would decrease (please see "Quote Six"). The decrease in productivity was a result of feeling uncomfortable, in what was thought to be an unstructured and uncertain environment. An environment where compensation was thought to be uncertain.

\section{Quote Six: "In terms of not receiving communication (about rules), it would} discourage me. I mean communication is essential" (Interviewee nine)

Clarity of gamification rules and purpose was an essential factor for the engagement of employees. Interviewees needed to have a sense that they could collaborate within their organisation. As recalled from the literature review (on page 14), it was noted that technology and software can act as communication system which assists in employees feeling like they are part of something whole, greater than an individual level (Kalinauskas, 2014) (Shpakova, Dörfler, \& MacBryde, 2017). However, findings tell a different story. For employees to feel a part of something whole, it was better having the ability to have access to gamification guidelines and communication with management in-person. Guidelines and communication with management did not necessarily need to be through technology and software (as communicated by “Quote Seven”).

\section{Quote Seven: "In-person communication of a point scoring system would be more valuable. It indicates that a higher-up is taking time out of their day. It's more sincere or personable, especially compared to getting information on an automated email" (Interviewee Two)}

In addition to effectively dealing with gamesmanship and promoting clarity, interviewees communicated that management needed to allow a sense of input within gamified work. Input in the sense of exploring gamification concepts within work meetings, which could ultimately lead to the implementation of desirable gamified elements. Having the ability to contribute in respect to idea generation and workplace elements, made employees feel like active and pleased team members (please refer to "Quote Eight" on the next page). 
Quote Eight: "My current manager allows me freedom to explore ideas and opportunities. Simple things like pitching ideas. This helps me be motivated on different levels. I think it definitely allows me to work that much harder"' (Interviewee Ten)

On the other end of the spectrum, interviewees indicated that if employees had minimal input, there was a negative impact on engagement. As communicated by "Quote Nine" below, if there was no perceived freedom to contribute to gamified workplace elements, employees had the potential to feel unsatisfied.

Quote Nine: “it (lack of freedom) wouldn't satisfy me, because I wouldn't feel like I helped shape the workplace, I'd be less motivated to compete" (Interviewee Five)

The overall desire for input within gamified work, illustrated that employees desire to collectively have some sense of autonomous influence separate from management. An influence which entails an input on the decisions normally associated with a manager. 


\subsection{Framing the Impact of Management Actions on Employee Engagement}

The correlation of high engagement levels with management eliminating gamesmanship, creating clarity, and fostering employee autonomy, are certainly interesting findings. Gamification-related literature and interview findings, undoubtedly emphasised the managerial avoidance of both unethical behaviour and an infringement of autonomy to evade disengagement (Spencer, 2013). However, the specific focus on managers executing actions to take authoritative control of gamesmanship, ensure clarity, and foster autonomy, were not evidently stated as precursors to higher levels of engagement. Tae Wan Kim's and Kevin Werbach's research, comes the closest to outlining the importance of management. The two authors framing of gamification-related ethical issues, proposed that practitioners and designers should not:

- Take unfair advantage of workers

- Infringe any involved workers' or customers' autonomy

- Intentionally or unintentionally harm involved parties

- Have a negative effect on the moral character of involved parties (Kim \& Werbach, 2016).

Furthermore, referring to Kim's and Werbach's framing of issues, illuminates insight into how some researchers have explicitly or implicitly tackled the topic of employee engagement within gamification. Some researchers have discovered and hypothesised research which correlates to a negative impact on employee engagement within gamification (i.e. infringing autonomy). Managerial actions promoting autonomy, the elimination of gamesmanship, and clarity of gamified rules and purpose, shed light on ways to positively impact employee engagement.

It was apparent that if an employee in New Zealand perceived that effective management was in place, then that employee would work more effectively and enjoy gamification at work. Conversely, employees who had a negative perception of their management team, indicated that they would be considerably less engaged while under conditions of gamification. Ultimately, this contrast led to the creation of "Figure Four: Gamified Perception Model", as seen on the next page. 


\section{Figure Four: Gamified Perception Model}

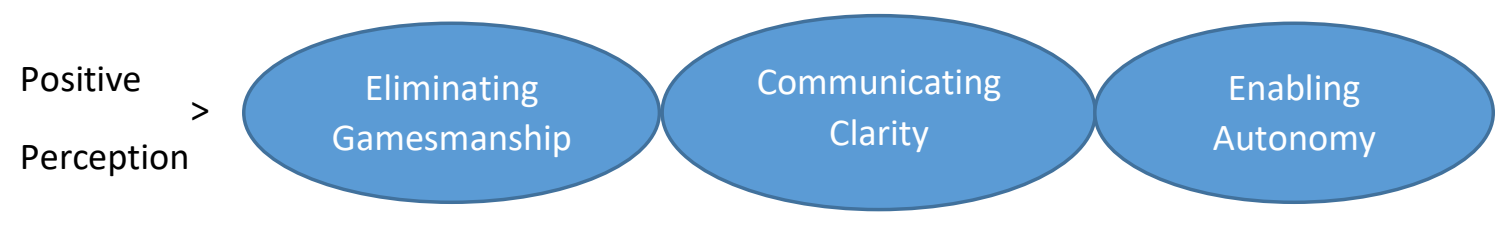

Perception Neutrality Line-

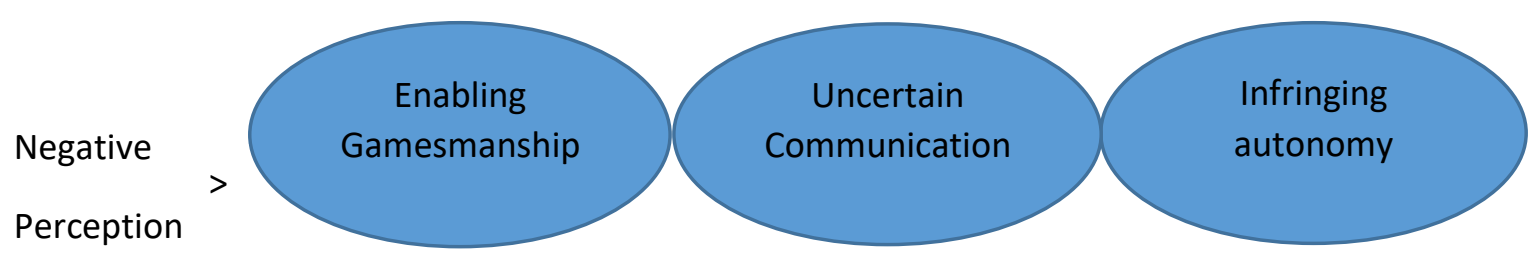

The Gamified Perception Model directly links three managerial undertakings (on the top half of the model), which were found to correlate to employees having a positive perception of managerial effectiveness. Eliminating gamesmanship (i.e. taking authority, punishing and monitoring foul play), communicating clarity (i.e. communicating gamification rules on a noticeboard, in-person interaction justifying gamification), and enabling autonomy (i.e. allowing employees to have input on gamification) meant employees perceived effective management was in place. A manager(s) would be wise, based on findings, to gain a positive perception or a perception of being effective as it associated with high engagement levels.

The Gamified Perception Model above, additionally links three other managerial undertakings (on the bottom half of the model) which were found to equate to a negative perception of managerial effectiveness. Based on findings, management would ideally avoid a negative perception due to the correlation with low employee engagement levels. To avoid a negative perception a management team should evade enabling gamesmanship (i.e. not having control of employee manipulation), uncertain communication (i.e. not communicating the purpose of gamification), and infringing employee autonomy (i.e. not permitting employee input).

Overall, the three managerial aspects that were found to dictate the level of employee engagement, indicates that a manager(s) needs an anthropological understanding of a workplace. An understanding that leads to knowing how employees feel about gamesmanship, the clarity of gamified rules and purpose, and input on gamification. 


\subsection{Investigating how Different Gamification Applications Impact Employee Engagement}

During interviews, participants were questioned about their thoughts and experiences pertaining to workplace gamification applications. The goal of enquiry was to investigate how specific applications influence employee engagement. As mentioned on page 30 of Chapter Two, the four most common workplace applications of gamification are

- Customisation- an ability to modify workplace surroundings and virtual aspects (i.e. virtual avatars and workplace screensavers) (Coppens, 2014).

- Intangible privileges- the ability to create and adapt work duties (i.e. time off) (Cheong, Filippou, \& Cheong, 2014).

- Leaderboards- physical or virtual boards which communicate the point totals of employees in relation to gamified work (Sarangi \& Shah, 2015).

- Physical rewards- compensation like gifts and vouchers (Sarangi \& Shah, 2015).

Interviewees provided discussion on the effectiveness of the four aforementioned gamification applications. Findings from those discussions will now be outlined.

\subsubsection{Customisation}

Workplace customisation was not held in a high regard by interviewees. However, participants did take a minor liking to the idea of modifying workplace surroundings (i.e. office news boards) and workplace applications (i.e. virtual avatars) (please refer to "Quote Ten”).

\section{Quote Ten: "customising avatars and boards is cool. It's not what I consider to be a main goal or fulfilling though" (Interviewee twelve)}

Considering participants minor liking, interviews indicated that customisation was not a significant reward. The point of customisation is providing freedom to employees. Furthermore, the freedom of modification within customisation was not deemed to be significant enough, especially in comparison to the application of intangible privileges. For instance, the freedom or autonomy in customising an avatar, paled in comparison to being able to create and adapt workplace duties (as communicated by Interviewee One below).

Quote Eleven: "I value freedom at work, but the freedom you get from customising an avatar and that, doesn't compare to the value of potential time off' (Interviewee One) 


\subsubsection{Leaderboards}

With workplace Leaderboards, there was a very minimal amount of interviewees (two) who were content with the application. Individuals who were satisfied with leaderboards being implemented, indicated a competitive frame of mind (as seen below with "Quote Twelve").

Quote Twelve: "Yes, competitiveness is healthy, I would do well with an organisational leaderboard. It only becomes unhealthy when you cheat or take the moral fun out of it" (Interviewee Ten)

Even though leaderboards satisfied a minimal amount of interviewees, leaderboards were not perceived positively in most interviews. Most interviews found that participants formed an objection to organisational leaderboards in workplaces. Opposition came in part from fear. The main concern was that leaderboards highlighted the weakest performing employees, which could subsequently make relatively low performing employees feel significantly incompetent. Incompetent to the point of workplace productivity or engagement decreasing overall, as seen with “Quote Thirteen”.

Quote Thirteen: "The top people, stay on the top. It really has the potential to name and shame people who are underperforming. And that's fine to some degree but people have actually resented workplaces because of that. Boards tend to name and shame people who are underperforming. Sometimes leaderboards fit, other times not” (Interviewee Three)

Additionally, employees also did not like the idea of colleagues having the ability to view scores. A lack of privacy when it came to productivity was communicated to also lead to a potential resentment of a workplace (please refer to Quote Fourteen” below).

Quote Fourteen: "I would hate it if there was a leaderboard in place. I mean I can't really get behind that. I just wouldn't work well. Any kind of system that involves forceful competition wouldn't be great" (Interviewee Nine) 


\subsubsection{Intangible Privileges}

In contrast to leaderboards, the application of intangible privileges was perceived in an extremely positive light. Intangible privileges such as the ability to work towards increased break time (i.e. increases of twenty-minute breaks to thirty-minute breaks), control of tasks (i.e. dictating work projects), and time off (i.e. going home early) were discussed. Ultimately, the opportunity for increased breaks, control, and time off work, correlated with employees desire to be more flexible in day-to-day life. Flexibility in terms of time was absolutely critical to interviewees. The value of intangible privileges to employees was communicated through "Quote Fifteen".

Quote Fifteen: "Time off is essentially the carrot at the end of the stick. The ability to work for two-hour lunch breaks instead of one, would motivate my work level. Back when, in my early work something was sort of similar called flexitime, which can be good" (Interviewee Three)

Essentially, all interviewees in some way viewed time as a valuable commodity in relation to work, as "Quote fifteen" above indicates. The communicated value of time correlates with the overall trend of employees' globally experiencing "time poverty", the belief that there is little time for leisure (Williams \& Masuda, 2016). Time poverty being an issue for interviewees makes sense. When interviewees would provide a background of their daily routines, there were many interests that were separate from work (i.e. interests in start-ups, family commitments, and special events). Therefore, an ability to gain flexibility in break time, control of tasks and time off, provided a chance to become less stressed at work and to acquire more time for other non-work commitments (please refer to "Quote Sixteen").

\footnotetext{
Quote Sixteen: "Time off is essential. I have so many responsibilities which especially revolve around my family, chores, planning, those things. Family is a huge part of my life" (Interviewee Eleven)
} 


\subsubsection{Physical rewards}

In relation to employee engagement, the application of physical rewards within gamification was perceived to engage employees to a considerable extent. Physical rewards within interview discussion were gifts and vouchers. The provision of inexpensive physical rewards made employees feel appreciated, which is communicated by "Quote Seventeen" below

\section{Quote Seventeen: "Little things like coffee vouchers or gifts go a long way. A ten dollar coffee of muffin voucher shows appreciation for the work we do" (Interviewee six)}

Ultimately, physical rewards made employees feel valued. Valued as a result of feeling appreciated by colleagues, which in turn made employees feel more connected to their counterparts (please see "Quote Eighteen”).

Quote Eighteen: "All I really need is a pat on the back. But getting something from a manager or workmate would definitely help in workplace relationships" (Interviewee One) 
4.6 Framing the impact of Gamification Applications: There needs to be a level of consideration pertaining to employees psychological needs

When analysing the qualitative data pertaining to gamification applications, there was a clear order of impact connecting to employee engagement. Gamification applications ordered based on their positive engagement impact were (from highest engagement to lowest engagement):

1. Intangible privileges

2. Physical rewards

3. Customisation

4. Leaderboards

When further analysing qualitative data, gamification applications were found to significantly relate to self-determination theory. As recalled from Chapter One, self-determination theory states that individuals have innate psychological needs (i.e. relatedness, autonomy, competence), which when fulfilled, can foster engagement and create self-regulated behaviour/engagement (Frost, Matta, \& Macivor, 2015). Specifically, the thesis study found gamification applications provided a pathway to satisfying specific psychological needs, which therefore impacted engagement.

The application of intangible privileges for New Zealand employees strongly related to the satisfaction of autonomy, a psychological need within self-determination theory. Opportunities for increased breaks, control, and time provided an avenue for employee autonomy, something highly valued based on the desire to be more flexible in day-to-day life. Furthermore, when looking at data throughout the study, autonomy was a core psychological requirement employees needed to have. For instance, interviewees had an overall desire for input within gamified work, an essential aspect of the Gamified Perception Model (explained in further detail on pages 53-54). To contrast, there was a stark difference between happiness and fulfilment with employees who had freedom at work (please see "Quote Nineteen"), and employees who perceived they lacked autonomy (please refer to "Quote Twenty" on the next page).

Quote Nineteen: "We have autonomy in that everyone is responsible for teaching their own classes all day. That in a way lets me know that I'm treated fairly and shown respect. To know that my opinion matters and I am able to have a voice in the decision-making that affects me" (Interviewee Six) 
Quote Twenty: "I execute routine tasks that don't particularly deviate. Honestly the consistency irritates me. I constantly need to be challenged in a way that stimulates my brain. Not challenged in a way in the sense of a test of willpower" (Interviewee Two)

Ultimately, with intangible privileges strongly satisfying the psychological need of autonomy, it led to a strong correlation to high engagement.

The workplace application of customisation also relates to the fulfilment of autonomy. However, as recalled from Subsection 4.5.1, interviews indicated that customisation was not significant in relation to autonomy, especially in comparison to the freedom gained from intangible privileges (please see "Quote Eleven" being reiterated below). With customisation not satisfying the need for autonomy significantly, customisation resulted in minimal employee engagement.

Quote Eleven: "I value freedom at work, but the freedom you get from customising an avatar and that, doesn't compare to the value of potential time off" (Interviewee One)

The use of physical rewards in the workplace was found to result in considerable engagement. Engagement was a result of employees feeling "appreciated" by colleagues. The appreciation directly linked to employees feeling more connected with their counterparts. In this sense, physical rewards provided an avenue to fulfil the psychological need of relatedness.

Overall, workplace leaderboards were found to relate to the psychological need of competence. The initial thought heading into the study was that leaderboards could satisfy employees' need for competence through perceived positive feedback and recognition. However, it was found that leaderboards actually had a negative relationship with competence. Specifically, based on findings leaderboards had the ability to diminish an employee's competence (please see "Quote Thirteen" reiterated below).

Quote Thirteen: "The top people, stay on the top. It really has the potential to name and shame people who are underperforming. And that's fine to some degree but people have actually resented workplaces because of that. Boards tend to name and shame people who are underperforming" (Interviewee Three) 
Gamification applications and their relationship with psychological needs, and therefore engagement, created an opportunity to create a framework. The relationships throughout Section 4.5 and Section 4.6, led to the creation of "Figure Five: Gamification Application Framework".

Figure Five: Gamification Application Framework

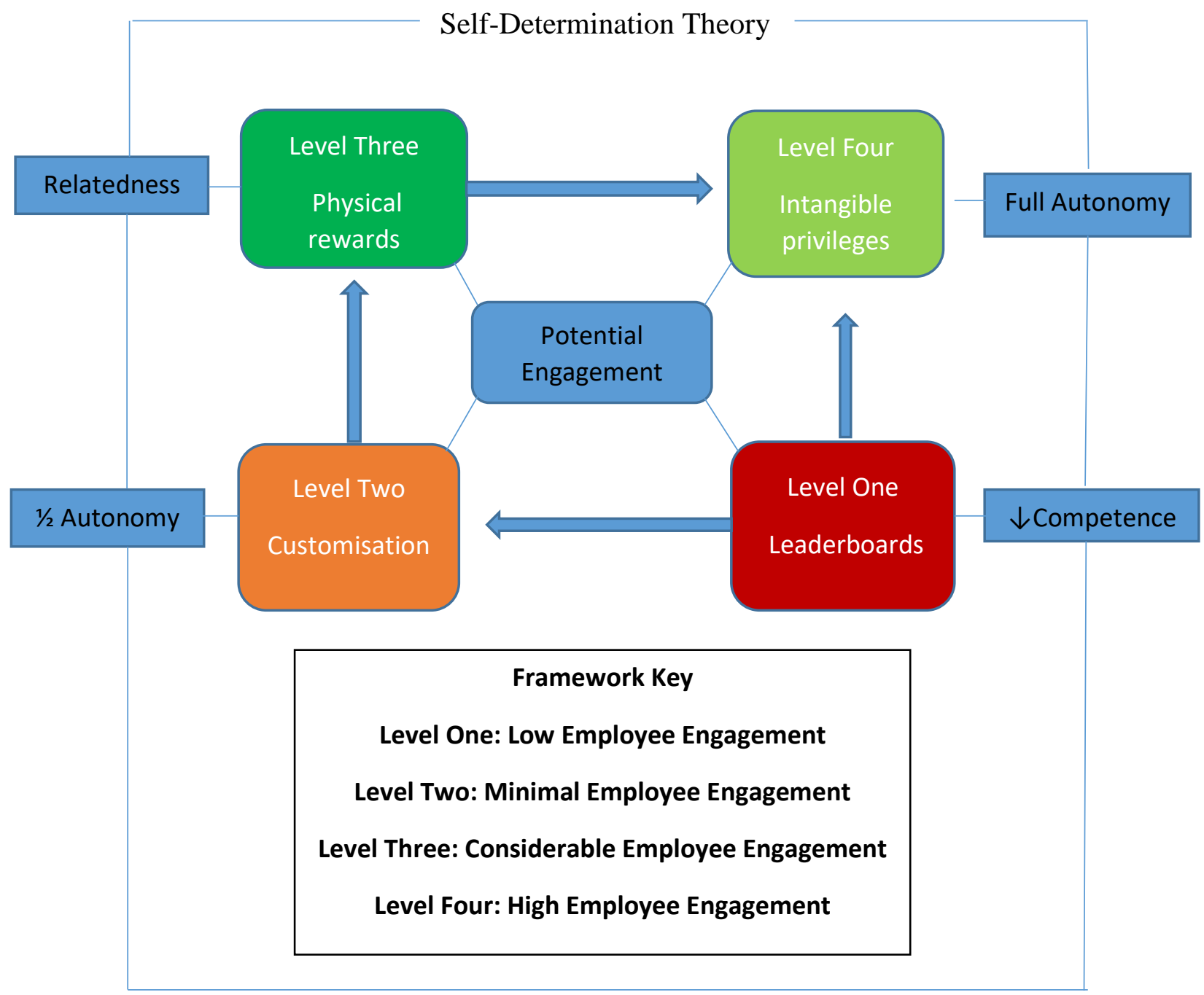

The Gamification Application Framework, attempts to illustrate findings pertaining to the four primary workplace gamification applications, and their relationships with employee engagement. The aim of the framework is to give interpreters knowledge on the effectiveness applications have on employee engagement. Pointed arrows attempt to guide viewers to what was found to be the most engaging application. Levels, supplemented with a "Framework Key", aim to be indicative of each application's impact on employee engagement (Level One being worst, Level Four being best). Colours also are a form of communication. For instance, 
the colours associated with the four levels flow from red for Level One (normally associated with negativity or stopping) to bright green for Level Four (normally associated with positivity and permission).

- "Level One Leaderboards" attempts to illustrate findings pertaining to leaderboards being indicative of low employee engagement (as emphasised in the Framework Key). Leaderboards relationship with the psychological need of competence is communicated negatively. The negative relationship is indicated with the symbol “ $\downarrow "$. An arrow pointing down attempts to indicate that competence is not a need in which employees can adequately satisfy through leaderboards.

- "Level Two Customisation" is suggestive of minimal engagement. Customisation is linked with " $1 / 2$ Autonomy", which suggests that customisation does not provide the best avenue for satisfying the psychological need of autonomy.

- "Level Three Physical rewards" specifies considerable engagement. The application of physical rewards is connected with the psychological need of relatedness. The connection indicates that physical rewards provide an acceptable path to satisfying relatedness.

- "Level Four Intangible Privileges" represents the highest potential for employee engagement. Intangible privileges association with "Full Autonomy", suggests that the need for autonomy can be fulfilled with the gamification application which was found to have the most positive impact.

Ultimately, based on the Gamification Application Framework, a manager would be wise to implement certain gamification applications. Specifically, the applications of intangible privileges and physical rewards which were found to correlate with high and considerable engagement. 


\subsection{Interviewees and their Player Types}

Based on the research of this thesis, it was deemed appropriate to understand and investigate player types pertaining to interviewees. Appropriate because research indicated that recognising and understanding player types in a workplace setting, could assist to a "plan in how to motivate/engage" (Marczewski, 2013). The type of understanding which could assist analysis of employee engagement and gamification installation. To understand player types within thesis research, qualitative analysis of each participant's interview transcript and email answers (containing one question relating to player types) was executed. Through a comparison of player type categories traits in relation to data were identified, and the allocation of player type categories (i.e. Achiever, Free Spirit, Philanthropist, Socialiser) was accomplished for all twelve interviewees.

\subsubsection{Achievers}

Overall, there was a total of 4 interviewees who were determined to be Achievers. Those who identified as Achievers favoured scenarios in which they were rewarded or recognised for completing tasks. Obtaining the recognition of colleagues was a primary driver of behaviour. What separated Achievers from other player types was their perception that their output was higher relative to other workers. Achievers ability to dedicate themselves and execute "hard work", was based on their recognition-oriented behaviour. "Quote Twenty-one" below, illustrated the personality traits and modes of thinking identified Achievers had.

\section{Quote Twenty-one: "Really my goals require a lot of hard work and dedication. If I don't take work seriously my designs won't get referenced at all. And with the future I'm trying to build, not getting noticed could be damaging to me as a brand" (Interviewee Five)}

The motives and actions of others employees in the workplace, had the potential to impact Achievers. Achievers needed to know that their colleagues had a somewhat "high work ethic" in order to accomplish joint success. Additionally, it was important that the motives and actions of colleagues did not interfere with an Achiever's daily and career goals. Achievers had a very goal-oriented path. If other workmates motives distracted an Achiever from their goals, it would result in frustration (please see "Quote Twenty-two" on next page). 
Quote Twenty-two: "As long as the end result is desirable I guess people having different motives is ok as long as they don't interfere with others. But with people being different, I would feel it wouldn't be fair if people didn't work as hard as me. In my experience a high work ethic being shared means a better end result" (Interviewee Five)

\subsubsection{Free Spirits}

"Free Spirits" were found, as literature states, to identify as individuals who do not desire to be restricted in how they worked. The two interviewees recognised as Free Spirits communicated that the ability to attain autonomy within work activities was their primary concern.

Free Spirits differentiated from Achievers in the sense that employee counterparts largely did not impact their methods of thinking. However, those in a powerful role (i.e. management) and their actions did concern Free Spirits, which is assumed to be because such roles have the ability to implement restriction (please refer to "Quote Twenty-three")

Quote Twenty-three: “motives like my team members don't influence me. Really the only motives that concern me are managers or those up the ladder" (Interviewee Twelve)

\subsubsection{Philanthropists}

The four individuals who were deemed as "Philanthropists", desired to give back to others. Based on the motives of those identified as Philanthropists, there was clearly a strong sense of selflessness for others and drive to accomplish an organisational purpose (please refer to “Quote Twenty-four”).

Quote Twenty-four: "I have always enjoyed working as a team member and believe that if we were to all work for each other the greatest outcome could be achieved. In my mind rewarding teammates through hard work earns better rewards not just for myself but others" (Interviewee One) 
Motivation for the most altruistic player type came from being able to elevate others and feeling fulfilment. Overall, Altruism was extremely evident from Philanthropists. Instead of being selfinterested in achieving individual goals, Philanthropists were significantly more team-oriented than other interviewees. The motives of others in the workplace did not seem to impact Philanthropists. Philanthropists were considerate of others to the point where they would potentially sacrifice their satisfaction (communicated with "Quote Twenty-five" below).

Quote Twenty-five: "Leaderboards aren't for me, but if a majority of my team were wanting to gain points then I would be for it. A scoring system could work as long as those participating in it were willing to keep on trying to score" (Interviewee Ten)

\subsubsection{Socialisers}

The two participants who identified as Socialisers communicated that they viewed networking as a chance to increase employment opportunities. Socialisers desired work opportunities like the interaction with certain individuals which could result in future utility (please refer to "Quote Twenty-six" below).

Quote Twenty-six: "In my mind networking would increase my own employability and increase the likelihood of future opportunities. Opportunities don't create themselves, others can definitely provide success or the stepping up of a ladder in the company" (Interviewee Two)

Overall, if Socialisers had great interaction with others, then their happiness would increase. Socialisers perceived even interaction outside of the workplace would lead to higher engagement and employee cohesion. 


\subsubsection{Conclusion of player type analysis}

Overall, an analysis and allocation of player types validated that there can be a multitude of desires within work. A difference of personality to the point of potentially impacting happiness and frustration in a workplace. In this sense, the potential impact of multiple personalities further validated the evolution of management relating to gamification. The evolution from utilising rational economic ideologies to behavioural economic ideologies, in order to cater to the differences of individual employees (mentioned in Chapter Two on page 18) (Vassileva, 2012) (Baptista \& Oliveira, 2017). Additionally, an allocation and analysis acquired information about how certain player types were impacted by other employees. For instance, Achievers were found to be the most impacted by other employees' motives, whereas other player types seemed more likely to perform in conjunction with workers regardless.

With all things considered, there would be a significant problem with using identified interviewee player-types as a basis for gamification structure. That problem is, all interviewees regardless of player type had their unique qualities or preferences. Not one interviewee corresponded to being a "pure" Achiever, Free Spirit, Philanthropist, or Socialiser. For instance, Achievers by description are supposed to exert great effort to acquire points and prestige through gamified techniques like leaderboards (Chou, 2016) (Androich, 2011). But some interviewees who best identified as Achievers disliked the very premise of leaderboards (please see "Quote Fourteen" said by an identified Achiever reiterated from Subsection 4.5.2)

\section{Quote Fourteen: "I would hate it if there was a leaderboard in place. I mean I can't really get behind that. I just wouldn't work well. Any kind of system that involves forceful competition wouldn't be great" (Interviewee Nine)}

For further reference of employees not fully aligning with player types, there were identified Philanthropists who valued leaderboards significantly more than any Achiever (please see "Quote Twelve" said by an identified Philanthropist reiterated from Subsection 4.5.2)

\footnotetext{
Quote Twelve: "Yes, competitiveness is healthy, I would do well with an organisational leaderboard. It only becomes unhealthy when you cheat or take the moral fun out of it" (Interviewee Ten)
} 
Overall, player types helped form a unique understanding of personality traits. However, those personality traits did not necessarily indicate gamification structure.

In reference to forming adequate gamification structure, another method found by way of previous analysis (in Section 4.5 and Section 4.6) is potentially a suitable option. That option is creating gamification structure based on the understanding of employees' psychological needs. Specifically, psychological needs relating to self-determination theory which are autonomy, relatedness, and competence. For example, through understanding employees need for autonomy, it would determine if the application of intangible privileges would be beneficial (i.e. if there is a significant need for autonomy, intangible privileges would likely result in high employee engagement). By comprehending employees' desire for relatedness, the level of expected engagement from physical rewards could be evaluated. By comprehending employees' feelings about competence, an anticipation of engagement in relation to leaderboards could be gathered.

Investigating player types is definitely an area that could use development. Specifically, formulating an evaluation system which determines player types could be worthwhile. As recalled from Chapter Two (on page 25), there is a test which helps determine an individual's player type, "The Bartle Test of Gamer Psychology". However, Bartle's assessment was specially designed for gaming contexts (i.e. online games), and the test created in 1999 may be considered outdated anyway. With all thing considered, even an updated test may be regarded as invaluable if gamification structure can be successfully established on the understanding of employees' psychological needs 


\subsection{Gamification and its Alignment with Generations and Work Fields}

Reviewed research in Chapter Two, suggested that the time period individuals were born and the work field of an individual, might be useful indicators for the level of engagement an employee may obtain from gamification. Specifically, research stated that gamification, in terms of engagement, would be best fitting for younger generations (i.e. Millennials and Generation Z) and for individuals working with technology (Werbach \& Hunter, 2015) (Campbell, 2016) (Caul \& Roberts, 2015) (Disys, 2017).

When isolating and contrasting transcript analysis of those who were Millennials and a part of Generation Z, it was found that gamification may not be relatively more engaging for younger generations. Participants of both younger and older generations communicated that gamification was not age relative. Instead, participants communicated that gamification was based on an individual's personality, specifically their competitive spirit (please refer to "Quote twenty-seven" said by a Generation Z interviewee, and "Quote twenty-eight" said by a Generation X interviewee).

\section{Quote Twenty-seven: "Everybody is different no matter what age, you'll have people who are competitive and like games and people who really do not"'(Interviewee One)}

\section{Quote Twenty-eight: "I think (gamified engagement) is dependent on the individual. Some strive and work well in a competitive setting. It's not age relative" (Interviewee Ten)}

It would be easy to think that Millennials would benefit from gamification in the workplace, due to systemic changes within not just workplaces, but culture too. The assumption is easy to make, and is made, because today's young working generations have endured:

- An overexposure to the rapid development of technology

- A reliance on technologies (i.e. software applications) which promote scoring and rewards Millennials

- A focus on the incorporation of innovation, change, and differentiation for competitive advantage (Werbach \& Hunter, 2015) 
However, findings indicated that younger generations were not significantly different compared to older generations. When interpreting both younger and older generations all had individuals who differed in gamification opinions. Some positive, some negative.

Additionally, when analysing the transcripts of those who worked significantly with technology, there wasn't a clear correlation between those who worked within the technology field and increased engagement. The analysis of transcripts again contradicted research indicating that gamification would be best fitting for individuals working with technology (Caul \& Roberts, 2015) (Disys, 2017).

Tech employees being more engaged from gamification may be overhyped due to the perception of the technology industry. The tech industry is thought to be synonymous with a culture of extreme innovation and differentiation, qualities which people would likely think strongly correlates with gamification's novel and unique nature (Boss, 2014). Based on findings, individuals who work with technology do not correlate with increased employee engagement from gamification.

Overall, there is another worthwhile point to note pertaining to findings indicative of there being no generational or technological alignment. That note is, if there is no alignment, it provides management with one less concern in terms of creating gamification structure. For instance, when planning for gamification, findings suggest an employee's age and work with technology would not require unique deliberation. 


\subsection{Concluding Chapter Four}

Twelve interviewees who spanned across generations, work fields, and player types, communicated essential information which has been communicated in Chapter Four. Information which significantly relates to the two research questions within this thesis. The qualitative analysis of content resulted in the creation of two illustrations, the Gamified Perception Model and the Gamification Application Framework. Additionally, analysis of player types indicated an alternative method to assist in creating gamification structure. Analysis also found gamification did not specifically align with younger generations and the technology industry.

Overall, based on Chapter Four we can answer the first research question presented in this thesis: How does gamification impact employee engagement in New Zealand? Gamification was found to impact employee engagement both positively and negatively in New Zealand. What dictated gamified employee engagement was two variables

1- Management actions within gamification

2- Gamified applications in relation to psychological needs

For high levels of employee engagement in New Zealand, management within gamification required a positive perception pertaining to managerial effectiveness. A positive perception was gained through management being able to eliminate employee gamesmanship, communicate clarity of gamification rules and purpose, and enable employee autonomy. Conversely, if managers enabled gamesmanship, did not communicate the purpose of gamification, and infringed employee autonomy, it equated to a negative perception of managerial effectiveness. A perception of managerial ineffectiveness correlated with low engagement levels. The need for effective management in a sense should come as no surprise. Even with famously productive work processes like Lean Six Sigma and Henry Ford's assembly line, there was a need to cater to employees (Hounshell, 1988). Gamification was found to be no different.

Gamified applications within workplaces had a significant impact on employee engagement in New Zealand. The result of significant impact was due to applications providing a path to satisfying the psychological needs of New Zealand employees, in relation to self-determination theory. Employees' will to fulfil certain needs, dictated their engagement from applications. For instance, New Zealand workers strong desire to satisfy autonomy resulted in employees working harder to receive intangible privileges. To contrast, New Zealand employees had a 
lack of desire to satisfy the need of competence, due to negative work implications which therefore resulted in the application of leaderboards correlating with low engagement.

It seems that gamification can be a viable option to increase the troublesome state of employee engagement in New Zealand (Gallup, 2016). To increase engagement is not without considerable effort, however. Management would need to constantly satisfy employees within gamification in order to be perceived as effective. Management would also need to constantly evaluate the psychological needs of employees, in order to implement apt gamification applications. Applications within a work process which have garnered scepticism due to a lack of empirical evidence (Ruhi, 2015). Even with the significant managerial effort and perceived "risk" required with gamification, the work process with the right managerial actions and applications could result in more engaged employees in New Zealand.

Chapter Four also communicated findings which answered the second research question within this thesis: How can gamification be successfully installed within New Zealand workplaces? Instead of answering the second research question in this chapter, it was deemed better to provide a solution in Chapter Five: Implications of Research. The content that helps answer the second research question has been amalgamated into a managerial guide, which represents a practical implication of research. 


\section{Chapter Five: Implications of Research}

The implications acquired from research come in many shapes and forms, but can be categorised as either practical or theoretical (Drotar, 2008). Chapter Five communicates the implications gained from the research presented in this thesis. A practical guide attempts to answer the second research question within this thesis. Theoretical implications aim to relate to previous research which has been reviewed.

\subsection{Practical Implications of the Research}

Based on research findings outlined in Chapter Four, a "Five Step Guide to Installing Gamification in New Zealand Workplaces" was formulated. This guide addresses the second research question within this thesis, by forming a managerial guide for installing gamification successfully within New Zealand. Before communicating the five steps, it should be noted that the guide does not take into consideration generational or industry related factors. Based on qualitative analysis, there was no strong evidence of generational or work field alignment with gamification.

Step one: Firstly, before anything else, a manager/decision maker needs to gain or maintain a positive perception pertaining to managerial effectiveness. Findings within gamification indicated a positive perception correlated to higher engagement, whereas a perception of ineffectiveness linked with low levels of engagement. Attaining a positive perception initially before gamification is implemented, gains a sense of preliminary trust from employees. Management actions that resemble authority, communication skills, and increasing employee autonomy best position management from the outset.

Step Two: The second step to installing gamification is executing an assessment of employees. Findings indicated that assessment should not concern player types, as each New Zealand employee has unique personality traits which equate to "pure" player types being non-existent. Instead, there needs to be an assessment of employees' psychological needs in relation to selfdetermination theory (i.e. autonomy, relatedness, competence). New Zealand employees strongly desired to satisfy autonomy, which therefore provides an initial starting point of assessment. Management actions that resemble increased employee autonomy in step one, can from a basis of initial evaluation. If initial increases in autonomy results in higher engagement, it indicates that autonomy will be highly valued in gamification. Employees also need to be assessed in relation to relatedness and competence to validate the use of physical rewards or leaderboards. 
Step Three: Thirdly, before gamification implementation, it is essential for there to be a clear communication of gamification rules and purpose. In this regard, the use of noticeboards and in-person employee interaction with management was found to be of significant value, and should be implemented. Research indicated that if New Zealand employees had a lack of information pertaining to gamification rules and purpose, the lack of clarity led to low levels of engagement. On the contrary, when employees knew gamification rules and purpose they felt more in tune with an organisation, consequently operating at a high level of engagement.

Step Four: The fourth step of the guide is implementing gamification. Gamification applications which positively correlate with the psychological needs of employees need to be implemented. Based on the findings of New Zealand employees' strong desire to fulfil autonomy, there should be the application of intangible privileges within New Zealand workplaces. As previously mentioned, there is always the chance assessment results in the indication of other applications. While implementing and executing gamification, the promotion of autonomy and elimination of gamesmanship should be pursued. Also, the continuation of clarity from management should occur. The aforementioned actions were found to result in a consistent positive perception of management, which as previously mentioned is critical.

Step Five: The last stage of the five step guide is assessing and adjusting the gamification at hand when appropriate. Step five essentially entails a critical evaluation and action period. Being able to recognise and act on potential faults will result in higher engagement levels.

"Figure Six: Five Step Guide to Installing Gamification in New Zealand Workplaces", is illustrated on the next page. The visualisation also represents a cycle. The cyclical nature indicates that there is a constant iteration of work needed within the complexity of gamification. Gamification being complex in the sense of needing to constantly act, assess and communicate. 
Figure Six: "Five Step Guide to Installing Gamification in New Zealand Workplaces

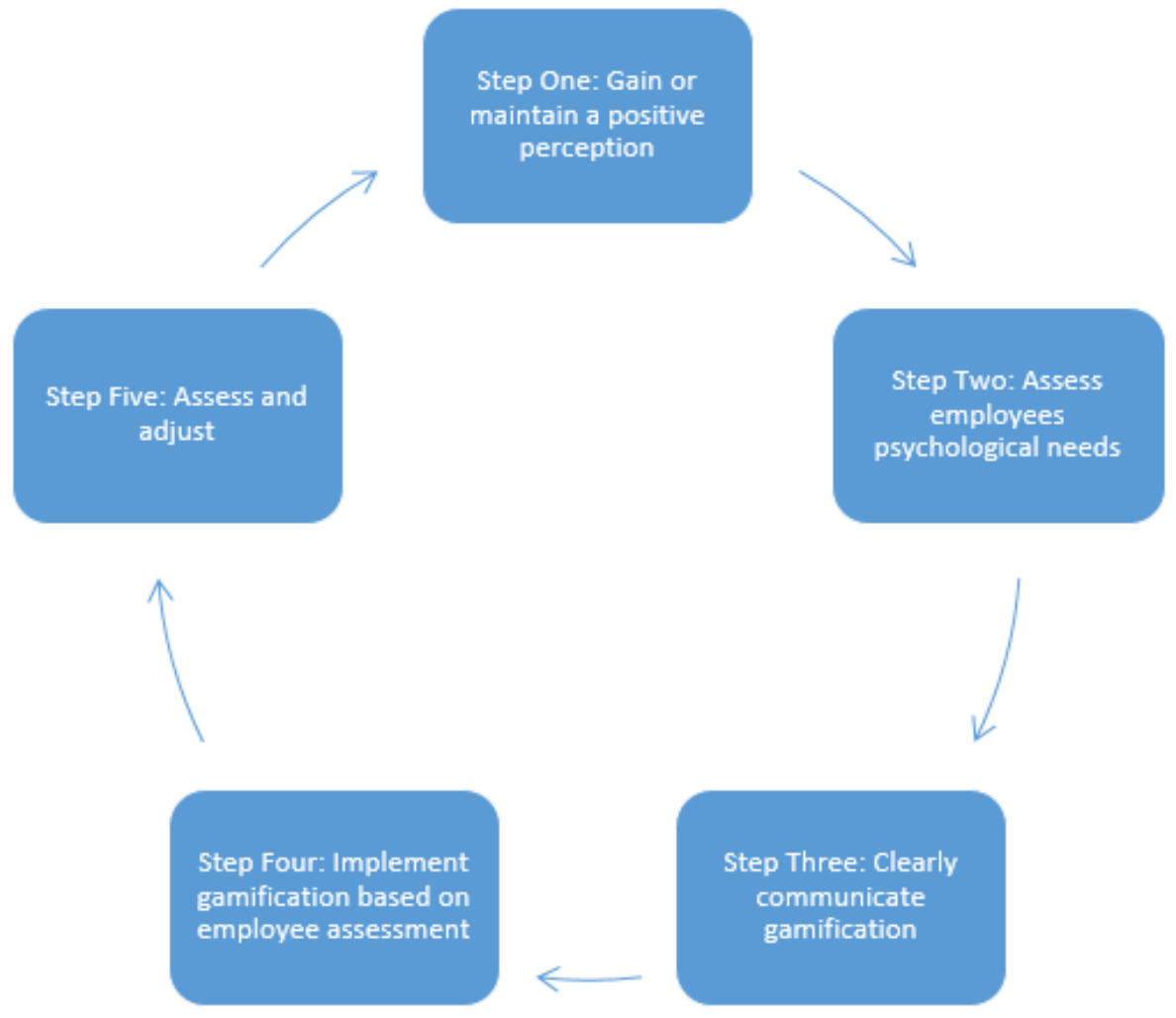

The hope with the Five Step Guide to Installing Gamification in New Zealand Workplaces, is to present information that answers the second research question within this thesis: How can gamification be successfully installed within New Zealand workplaces? Additionally, the guide hopes to communicate that gamification can be successfully installed in New Zealand Workplaces if:

- Management has a positive perception of effectiveness through clarity, autonomy, and authority

- There is a successful acknowledgement of employees psychological needs which correspond to gamification applications

- There is an acknowledgement that gamification is a process of putting forward effort with complexities

In conclusion, the five step guide provides a manager with an amalgamation of practical methods to successfully install gamification in New Zealand workplaces. 


\subsection{Theoretical Implications of the Research}

A key area in gamification has been the theoretical use of player types in assisting gamification structure (Kalinauskas, 2014). The analysis and allocation of interviewee player types within this thesis, indicated a unique form of understanding personality traits. However, those traits did not necessarily indicate a way to form an engagement inducing structure, as no interviewee identified as a "pure" player type. The findings in this thesis indicate that player type research needs development in regard to workplace applicability. Future research concerning player types needs to avoid isolating individuals as pure Achievers, Free Spirits, Philanthropists, or Socialisers. Instead, there could be research indicating a quantifiable number allocated to individuals i.e. 70\% Achiever, 20\% Socialiser, 5\% Free Spirit, 5\% Philanthropist. Having a more descriptive representation of player types, could result in the avoidance of typecasting employees with unfitting gamification applications. For reference, the commonplace typecasting of Achievers and leaderboards, was found to correlate with low engagement levels (please see page 67). Quantifying player types within workplaces would be difficult, with player types being an undeveloped research area. To progress towards more descriptive information, there would need to be more exploratory research executed initially. However, academics seem reluctant to explore, as player type research has been referred to as "the next step" of gamification research with little action (Cheong, Filippou, \& Cheong, 2014).

In reference to forming adequate gamification structure, another method found by way of research was deemed better than utilising player types. That alternative method was creating structure based on employees' psychological needs, relating to self-determination theory. Throughout research reviewed in Chapter Two, there was not a specific linkage of autonomy, relatedness, and competence with the application of intangible privileges, customisation, physical rewards and leaderboards. A future study with a more concentrated approach could validate the needs-based method that has been communicated in this thesis. Alternatively, the needs defined outside of self-determination theory, could be investigated in relation to gamification structure. One theory relating to the needs of employees that may interest management academics, is Abraham Maslow's hierarchy of needs concept. For instance, using needs like "physiological”, "safety”, "belonging”, “esteem”, and "self-actualization" needs, in relation to gamification could form a basis for interesting findings (Hagerty, 1999). Such a wide range of employee need analysis, could result in a wide range of innovative gamification practices being evaluated and implemented. 
Potentially the most significant value in this thesis, is the communication of precursors to increase employee engagement. The majority of gamification research has discovered and hypothesised research, which correlates to a negative impact on employee engagement (i.e. infringing autonomy) (Kim \& Werbach, 2016). Precursors discovered like the promotion of autonomy, clarity, and gamesmanship elimination, provide ways to positively impact employee engagement. Of course, these precursors can be used practically (i.e. in the Five Step Guide to Installing Gamification in New Zealand Workplaces). But also these precursors provide evidence that gamification, if manged well, has the ability to increase engagement. For widespread use of gamification there will need to be research which additionally provides a positive correlation with engagement. If there is enough favourable empirical evidence companies like IBM, Coca-Cola, and SAP (referred to on page 21) may have less reservations about gamification (Kim \& Werbach, 2016). 


\section{Chapter Six: Limitations of the Research}

Chapter Six outlines the characteristics of research design which impacted or influenced the interpretation of findings, otherwise known as limitations of research. Overall, Chapter Six identifies limitations, reflects on identified boundaries, and suggests potential solutions to deal with the specified limits in the future.

As previously explained in "Section 3.5", the methodology utilised in this thesis is not without flaws. To begin with, the interpretive paradigm was relied upon in this thesis, which influenced flow-on decisions. Decisions like using a qualitative approach and incorporating phenomenology methods like bracketing. Essentially, research by means of the interpretive paradigm meant the neglect of a positivist approach and quantitative techniques. Taking an alternative approach to research like incorporating a mixed-method approach, could have broadened research methods (i.e. data being collected via surveys, analysis through statistical inferences) which could have produced unique findings. However, research conducted through the interpretive paradigm was perceived to be best fitting, with applied methods relating to research justification throughout Chapter Three. It would have been interesting to have conducted research through alternative means. Although, with all things considered, if this study was executed again the same methods would have been utilised based on interpretive paradigm suitability.

There was another limitation regarding the use of qualitative research, in terms of qualitative investigation being partly made on the basis of personal interpretation. Before deciding to conduct research on gamification, the work process was a topic which interested the primary investigator beforehand. Interest was a result of genuine curiosity in how workplaces could potentially elicit productivity. Based on interest, interaction and a brief research review about gamification topics, commenced twelve months before initiating research. Some would argue that a genuine interest in a topic over a twelve month period, could have provided time for a researcher to generate biased opinions about gamification aspects. However, it could also be argued that an interest in a topic and subsequent research was a strength. An advantage in terms of having a greater idea of gamification and its "ins" and "outs". If in the same situation again, investigation of the thesis topic would still be pursued due to the idea that genuine interest equates to enjoyable work.

Additionally, the sample selection of interviewee participants can also be viewed as a limitation. The subjectivity and non-probability based nature of selecting purposive ideals 
(outlined in Subsection 3.4.3), meant that certain interviewee requirements were idealised to be met. Requirements like participants having to work or be from the Wellington region, makes findings somewhat problematic in terms of generalisability. For instance, based on theories of national working differences (i.e. Hofstede's cultural dimensions theory), employees from other countries may experience dramatic differences in terms of gamified employee engagement (Hofstede, 2017). Therefore, in terms of generalisability findings may not be applicable to a large population. With all things considered however, conducting research in New Zealand was deemed to be advantageous, as New Zealand was a blank canvas or uncharted territory in relation to gamification research. Additionally, purposive sampling would be selected again based on the aspects of time, funds, and accessibility.

On the topic of sample selection, analysis could have been improved in relation to one key finding. There could have been a better sampling scheme, in order to better understand gamification's alignment with younger generations and the technology industry. Selection would have ideally utilised a comparative case study approach, comparing tech employees to non-tech employees. However, based on the broad objectives of this study concerning employee engagement in multiple areas (i.e. ethics, technology, player types etc.), it was deemed unfitting to utilise a case study approach concerning the technology industry. Ideally, it would be interesting for an academic to take a more concentrated approach, and conduct a comparative analysis between tech-industry and non-tech employees. If there was the chance to go back in time and conduct research, a sample of six employee involved with technology would have been desired, instead of the three employees analysed in this study.

The final limitation of research, was based on the subject of gamification itself. A restrictive factor with performing research concerning gamification, and the corresponding levels of engagement, was the amount of previous research within syndication. As previously mentioned in "Section 1.2", there is minimal literature exploring the impact that gamification has on employee engagement in New Zealand. To compound research scarcity, gamification's relationship with employees as a research area is in its infancy on a global scale, as the first connection between employees and gamification was published in 2012 (Neeli, 2012). Previous research and its scarcity created difficulties in terms of creating an appropriate methodology. It would have been pleasant to view the methodologies of more gamification studies, as it could have helped form research design. The lack of previous research in syndication resulted in going into the "unknown" so to speak. Nevertheless, going into the unknown would be pursued again. The exploratory nature of research was deemed exciting. 


\section{Chapter Seven: Conclusions of the Study}

Producing a thesis drew comparisons to the process of doing a giant, complex jigsaw puzzle. While the thesis was is in progress, the total picture which was being created looked vague, and lacked direction. However, with more effort the image slowly took form. "Chapter Seven: Conclusions of the Study" has been written because there is now a sense of completion. This chapter aims to summarise the main findings in this thesis.

Overall, it is perceived that this thesis could contribute to the management of gamification. The process of research extended to broad, or exploratory areas which elicited significant findings. Findings from qualitative data which partly resulted in:

- Discovering the significant impact of management actions within gamification

- Noticing a relationship between gamification applications and psychological needs

- A managerial guide created to ensure the successful installation gamification

- The discovery of precursors to increased engagement (i.e. the promotion of autonomy, clarity, and gamesmanship elimination)

- Illustrations related to gamification (i.e. the Gamified Perception Model and the Gamification Application Framework)

Through a review of research, formulation of a methodology, research actions, and analysis, the two research questions presented in this thesis can be answered. In regards to the first research question: How does gamification impact employee engagement in New Zealand? Gamification was found to impact employee engagement both positively and negatively in New Zealand. What dictated gamified employee engagement was two variables. These variables were management actions within gamification, and gamified applications in relation to psychological needs. Management within gamification required a positive perception, which could be acquired through managerial undertakings communicated on the "Gamified Perception Model” (on page 55).

In reference to the second research question in this thesis: How can gamification be successfully installed within New Zealand workplaces? Gamification can be installed in New Zealand workplaces through a five step process. The steps within the five step process are

1- Management gaining a positive employee perception

2- Assessing employees psychological needs

3- Clearly communicating gamification to employees before implementation 
4- Implementing gamification in relation to the psychological needs assessment in step two

5- Assessing and adjusting gamification if appropriate

Although there could always be more time put in, theoretical connections mentioned, and more deliberation, now is a time to take an objective stand and see the work as a whole, feeling that the pieces of the thesis puzzle have all fitted neatly together. Finally this thesis has taken form into a complete picture that hopefully is aesthetic! 


\section{$\underline{\text { References }}$}

Acocella, I. (2012). The focus groups in social research: advantages and disadvantages. Quality and Quantity, 1125-1136.

Aharonson, B. S., \& Schilling, M. (2016). Mapping the technological landscape: Measuring technology distance, technological footprints, and technology evolution. Research Policy, 81.

Al-Azawi, R., Al-Faliti, F., \& Al-Blushi, M. (2016). Educational Gamification Vs. Game Based Learning: Comparative Study. International Journal of Innovation, Management and Technology, 131-136.

Amos, E. A., \& Weathington, B. (2008). An Analysis of the Relation Between EmployeeOrganization Value Congruence and Employee Attitudes. The Journal of Psychology, 615-631.

Andonova, Y. (2013). Loyalty 3.0: How big data and gamification are revolutionizing customer and employee engagement. Journal of Marketing Analytics, 234-236.

Androich, A. (2011). Get in the Game. Marketing Magazine, 54-56.

Banerjee, D., \& Das, K. (2015). Smartphone Gaming in Indian Generation Y: An Exploration. Romanian Journal of Marketing, 54-66.

Banfield, J., \& Wilkerson, B. (2014). Increasing Student Intrinsic Motivation And SelfEfficacy Through Gamification Pedagogy. Contemporary Issues in Education Research (Online), 291-298.

Baptista, G., \& Oliveira, T. (2017). Why so serious? Gamification impact in the acceptance of mobile banking services. Internet Research, 118-139.

Barr, M. (2017, July 1). The Bartle Test of Gamer Psychology. Retrieved from matthewbarr.co.uk: http://matthewbarr.co.uk/bartle/index.php

Bartle, R. (1996, 28 August). HEARTS, CLUBS, DIAMONDS, SPADES: PLAYERS WHO SUIT MUDS . Retrieved from mud.co.uk: http://mud.co.uk/richard/hcds.htm 
Barton, J., \& Haslett, T. (2007). Analysis, synthesis, systems thinking and the scientific method: rediscovering the importance of open systems. Systems Research and Behavioral Science, 143-155.

Bergen, J. (2014, March 7). Deloitte's gamified recruitment video sets the bar high for interactive enterprise video. Retrieved from blog.raptmedia.com: http://blog.raptmedia.com/deloitte-interactive-enterprise-video/

Bergen, C. V., \& Bressler, M. S. (2011). TooMuch Positive Thinking Hinders Hinders Entreprenuer Success. Journal of Business and Entrepreneurship, 30-52.

Boddy, C. R. (2016). Sample size for qualitative research. Qualitative Market Research: An International Journal , 426-432.

Bogost, I. (2015). Why gamification is bullshit. In The gameful world: Approaches, issues, applications. Cambridge: MIT Press.

Boland, R. (1985). Phenomenology: A Preferred Approach to Research in Information Systems. Research Methods in Information Systems, 430-439.

Boss, J. (2014, October 20). How One Technology Company Is Leading A Culture Of Change. Retrieved from www.forbes.com: https://www.forbes.com/sites/jeffboss/2014/10/20/how-one-technology-company-isleading-a-culture-of-change-2/\#116c4f664916

Bowman, D. (2014). It's all in the game. Training Journal, 31-34.

Brand, V. (2009). Empirical Business Ethics Research and Paradigm Analysis. Journal of Business Ethics, 429-449.

Brooks, J., McCluskey, S., Turley, E., \& King, N. (2015). The Utility of Template Analysis in Qualitative Psychology Research. Qualitative Research in Psychology, 202-222.

Bump. (2017, Feburary 20). Here Is When Each Generation Begins and Ends, According to Facts. Retrieved from www.theatlantic.com: https://www.theatlantic.com/national/archive/2014/03/here-is-when-each-generationbegins-and-ends-according-to-facts/359589/

Burke, B. (2014). Gamify: How gamification motivates people to do extraordinary things. Brookline, MA: Biblomotion. 
Campbell, A. (2016). Technology drives employee wellbeing and engagement at Oracle. Occupational Health \& Wellbeing, 9.

Cardador, M. T., Northcraft, G., \& Whicker, J. (2017). A theory of work gamification: Something old, something new, something borrowed, something cool? Human Resource Management Review, 353-365.

Castro Soeiro, F., Santos, M., \& Alves, J. (2016). Network-based innovation: the case for mobile gaming and digital music. European Business Review, 155-175.

Caul, R., \& Roberts, J. (2015). Is the future game-based? Training Journal, 34-37.

Ceira, R. (2017, April 5). 13 Practices of the World's Most Innovative Organizations. Retrieved from www.innovationmanagement.se: http://www.innovationmanagement.se/2016/04/01/13-practices-of-the-worlds-mostinnovative-organizations/

Chamorro-Premuzic, T., \& et al. (n.d.). New Talent Signals: Shiny New Objects or a Brave New World?

Chen, C.-w., \& Koufaris, M. (2015). The impact of decision support system features on user overconfidence and risky behavior. European Journal of Information Systems, 607623.

Cheong, C., Filippou, J., \& Cheong, F. (2014). Towards the Gamification of Learning: Investigating Student Perceptions of Game Elements. Journal of Information Systems Education, 233-244.

Chou, Y.-k. (2016, August 28). User and Player Types in Gamified Systems. Retrieved from yukaichou.com: http://yukaichou.com/gamification-study/user-types-gamifiedsystems/

Chua, W. (1986). Radical Developments in Accounting Thought. The Accounting Review, 601-632.

Coppens, A. (2014, March 3). Gamification Mechanic Monday: customisation. Retrieved from gamificationnation.com: http://gamificationnation.com/gamification-mechanicmonday-customisation/ 
Crabtree, S. (2013, October 8). Worldwide, 13\% of Employees Are Engaged at Work. Retrieved from www.gallup.com: http://www.gallup.com/poll/165269/worldwideemployees-engaged-work.aspx

Crouch, M., \& McKenzie, H. (2006). The logic of small samples in interview-based qualitative research. Social Science Information, 483-499.

Darejeh, A., \& Salwah, S. (2016). Gamification Solutions to Enhance Software User Engagement - A Systematic Review. International Journal of Human - Computer Interaction, 613-642.

Davis, G. F. (2015, May 28). What Is Management Research Actually Good For? Retrieved from hbr.org: https://hbr.org/2015/05/what-is-management-research-actually-good-for

Davis, K., \& et al. (2012). Connecting across continents: collaborative learning in a Web 2.0 world. New Library World, 415-428.

DeLuca, D., Gallivan, M., \& Kock, N. (2008). Furthering Information Systems Action Research: A Post-Positivist Synthesis of Four Dialectics. Journal of the Association for Information Systems, 48-64.

Ding, Y., \& Chai, K. (2015). Emotions and continued usage of mobile applications. Industrial Management \& Data Systems, 833-852. .

Disys. (2017, July 2). Employee engagement and gamification in the tech sector. Retrieved from www.disys.com: http://www.disys.com/employee-engagement-andgamification-in-the-tech-sector/

Drotar, D. (2008). Thoughts on establishing research significance and presenting scientific integrity. Journal of Pediatric Psychology, 1-3.

Ellefson, A. (2016, March 22). Morning Mug: "Education Is The Movement From Darkness To Light." - Allan Bloom . Retrieved from www.sheepsheadbites.com: http://www.sheepsheadbites.com/2016/03/morning-mug-education-is-the-movementfrom-darkness-to-light-allan-bloom/

Etikan, I., Musa, S. A., \& Alkassim, R. S. (2015). Comparison of Convenience Sampling and Purposive Sampling. American Journal of Theoretical and Applied Statistics, 1-4. 
Fay, E., \& Riot, P. (2007). Phenomenological approaches to work, life and responsibility. Society and Business Review, 145-152.

Fröding, B., \& Peterson, M. (2013). Why computer games can be essential for human flourishing. Journal of Information, Communication \& Ethics in Society, 81-91.

Frost, R., Matta, V., \& Macivor, E. (2015). Assessing the Efficacy of Incorporating Game Dynamics in a Learning Management System. Journal of Information Systems Education, 59-70.

Gallup. (2016, August 28). The Engaged Workplace. Retrieved from www.gallup.com: http://www.gallup.com/services/190118/engaged-workplace.aspx

Gallup. (2017, May 5th). Gallup Q12® Meta-Analysis Report. Retrieved from www.gallup.com: http://www.gallup.com/services/191489/q12-meta-analysis-report2016.aspx?g_source=ServiceLandingPage\&g_medium=copy\&g_campaign=tabs

Gibbs, S. (2016, February 26). Mercedes-Benz swaps robots for people on its assembly lines. Retrieved from www.theguardian.com: https://www.theguardian.com/technology/2016/feb/26/mercedes-benz-robots-peopleassembly-lines

Gibson, L., \& Sodeman, W. (2014). Millennials and Technology: Addressing the Communication Gap in Education and Practice. Organization Development Journal, 63-75.

Guba, E. G., \& Lincoln, Y. (1994). Handbook of qualitative research In N. K. Denzin \& Y. S. Lincoln (Eds.). In Competing Paradigms in Qualitative Research (pp. 105-117). Thousand Oaks, CA: Sage.

Guest, G., Bunce, A., \& Johnson, L. (2006). How Many Interviews Are Enough? An Experiment with Data Saturation and Variability. Family Health International, 59-82.

Hagerty, M. R. (1999). Testing Maslow's hierarchy of needs: National quality-of-life across time. Social Indicators Research, 249-271.

Hamari, J. (2013). Transforming homo economicus into homo ludens: a field experiment on gamification in a utilitarian peer-to-peer trading service. Electronic Commerce Research and Applications, 236-245. 
Hamari, J., \& Eranti, V. (2011). Framework for designing and evaluating game achievements. DiGRA, (pp. 122-134). Hilversum, The Netherlands.

Hamari, J., \& Koivisto, J. (2015). Why do people use gamification services? International Journal of Information Management, 419.

Hamari, J., Koivisto, J., \& Sarsa, H. (2014). Does gamification work? A literature review of empirical studies on gamification. 47th Hawaii International Conference on System Sciences (pp. 3025-3034). Waikoloa, HI: IEEE.

Harbert, T. (2014). GIVING GAMIFICATION A GO. Computerworld, 12.

Harju, L. K., \& Hakanen, J. (2016). An employee who was not there: a study of job boredom in white-collar work. Personnel Review, 374-391.

Hays. (2016). STAFF ENGAGEMENT IDEAS FOR ACTION. Sydney: Hay Specialist Recruitment (Australia) Pty Limited.

Hays Specialist Recruitment. (2016, August 22). Staff engagement Ideas for action. Retrieved from www.hays.com.au: https://www.hays.com.au/staff-engagement/index.htm

Hess, J. D., \& Benjamin, B. (2015). Applying Lean Six Sigma within the university: opportunities for process improvement and cultural change. International Journal of Lean Six Sigma, 249-262.

Hofstede, G. (2016, August 25). National Culture. Retrieved from geert-hofstede.com: https://geert-hofstede.com/national-culture.html

Hofstede, G. (2017, July 8). National Culture. Retrieved from geert-hofstede.com: https://geert-hofstede.com/national-culture.html

Hofstede, G. (2017, January 31). New Zealand in comparison to the United States. Retrieved from geert-hofstede.com: https://geert-hofstede.com/new-zealand.html

Hounshell, D. A. (1988, November). Gamification being installed in a workplace even with the most advanced technology and creativity generation will not work if certain workplace dynamics are not considered . Retrieved from hbr.org: https://hbr.org/1988/11/the-same-old-principles-in-the-new-manufacturing

Hughes, D. O. (2016). Qualitative and Quantitative Approaches to Social Research. University of Warwick- Department of Sociology, 3. 
Incentive Research Foundation. (2017, March 31). Generations in the Workforce \& Marketplace: Preferences in Rewards, Recognition \& Incentives. Retrieved from theirf.org: http://theirf.org/research/generations-in-the-workforcemarketplacepreferences-in-rewards-recognition-incentives/1427/

Jacobs, D. (2016). GAME ON, LOAN OFFICERS. Mortgage Banking, 76.

Jong, M. (2015). Does online game-based learning work in formal education at school? A case study of VISOLE. The Curriculum Journal, 249-267.

Joorabchi, A., English, M., \& Mahdi, A. (2016). Text mining stackoverflow: An insight into challenges and subject-related difficulties faced by computer science learners. Journal of Enterprise Information Management, 255-275.

Kalinauskas, M. (2014). Gamification in Fostering Creativity: Player Type Approach. Socialines Technologijos, 385-400.

Kang, B. G., Edum-Fotwe, F., Price, A., \& Thorpe, T. (2014). The application of causality to construction business ethics. Social Responsibility Journal, 550-568.

Kapko, M. (2016). Why Slack should worry about Facebook, Microsoft and Google. CIO; Framingham, 1.

Kaplan, B., \& Maxwell, J. (1994). Qualitative Research Methods for Evaluating Computer Information Systems. Evaluating Health Care Information Systems, 45-68.

Kapp, K. (2012). The Gamification of Learning and Instruction: Game-Based Methods and Strategies for Training and Education . John Wiley \& Sons.

Kelley, T. M., \& Johnston, E. (2012). DISCOVERING THE APPROPRIATE ROLE OF SERIOUS GAMES IN THE DESIGN OF OPEN GOVERNANCE PLATFORMS. Public Administration Quarterly, 504-554.

Kim, J. T., \& Lee, W.-h. (2015). Dynamical model for gamification of learning (DMGL). Multimedia Tools and Applications, 8483-8493.

Kim, T. W., \& Werbach, K. (2016). More than just a game: ethical issues in gamification. Ethics and Information Technology, 157-173.

Kinash, S. (2017). Defining Research. Quality, Teaching, and Learning, 1-3. 
Kowalczyk, D. (2017, April 6). Purposes of Research: Exploratory, Descriptive \& Explanatory. Retrieved from study.com: http://study.com/academy/lesson/purposesof-research-exploratory-descriptive-explanatory.html

Kumar, H. (2015). Gamification, the finer art: fostering creativity and employee engagement. The Journal of Business Strategy, 3-12.

Kumar, J. M., Herger, M., \& Friis Dam, R. (2017, February). Bartle's Player Types for Gamification . Retrieved from www.interaction-design.org: https://www.interactiondesign.org/literature/article/bartle-s-player-types-for-gamification

Laczniak, R. N. (2004). From the Editor. Journal of Advertising, 5-6.

Landsell, J., \& Hägglund, E. (2016). Towards a Gamification Framework: Limitations and opportunities when gamifying business processes. Umea University, 1-62.

Lavigna, B. (2015). Why Employee Engagement Matters and Why Engagement Efforts Fail. Government Finance Review, 32-37.

Leppänen, A. (2008). Does multi-level intervention enhance work process knowledge? Journal of Workplace Learning, 416-430.

Leventhal, B. (2015). MRS Census and Geodemographics Group annual conference: Harnessing open data for business advantage. Journal of Direct, Data and Digital Marketing Practice, 236-238.

Little, B. (2015). Learning isn't changing. Industrial and Commercial Training, 330-335.

Lowman, G. H. (2016). Moving Beyond Identification: Using Gamification To Attract and Retain Talent. Industrial and Organizational Psychology, 677-682.

MacAulay, M. (2010). INTEGRATING LESSONS FROM OTHER DISCIPLINES. The Open Source Business Resource, 10-15.

Mack, T. C. (2014). Trends at Work: An Overview of Tomorrow's Employment Ecosystem. The Futurist, 14-19.

Marczewski, A. (2013, August 12). A New Perspective on the Bartle Player Types for Gamification. Retrieved from www.gamification.co: http://www.gamification.co/2013/08/12/a-new-perspective-on-the-bartle-player-typesfor-gamification/ 
Marczewski, A. (2016, February 26). Where is the Killer / Winner Type in your HEXAD? Retrieved from www.gamified.uk: https://www.gamified.uk/2016/02/26/killerwinner-types-hexad/

Marczewski, A. (2017, May 8). A Player Type Framework for Gamification Design. Retrieved from www.gamified.uk: https://www.gamified.uk/user-types/

McCormick, T. (2013). Anthropology of an Idea Gamification. Foreign Policy, 26-27.

McFarlane, A. (2016). Neal Stephenson's Reamde: A Critique of Gamification. Foundation; Dagenham, 24-36.

Mendelson, S. (2016, April 14). The Most Powerful Weapon for Changing the World: How Microfinance Institutions Can Increase Access to Education. Retrieved from http://nextbillion.net: http://nextbillion.net/the-most-powerful-weapon-for-changingthe-world-how-microfinance-institutions-can-increase-access-to-education/

Merriam Webster. (2017, January 28). Definition of Research . Retrieved from www.merriam-webster.com: https://www.merriam-webster.com/dictionary/research

Meyer, K., \& Kiyak, T. (2014). Proceedings of the 56th Annual Meeting of the Academy of International Business: "Local Contexts in Global Business". Academy of International Business.

Morgan, A. (2011). Inquiry, Investigating Our Experience in the World: A Primer on Qualitative. Knoxville: Univ Tennessee Press.

Nadin, S., \& Cassell, C. (2006). The use of a research diary as a tool for reflexive practice: Some reflections from management research. Qualitative Research in Accounting and Management, 208-217.

Neeli, B. (2012). A Method to Engage Employees using Gamification in BPO Industry. 2012 THIRD INTERNATIONAL CONFERENCE ON SERVICES IN EMERGING MARKETS (ICSEM) (pp. 142-146). Mysore: IEEE.

Noyes, K. (2015, April 28). Can gamification solve enterprises' engagement problem? Retrieved from www.reseller.co.nz: https://www.reseller.co.nz/article/573572/cangamification-solve-enterprises-engagement-problem/ 
Nuki, P. (2016, September 1). How gamification is getting us moving in the workplace. Retrieved from www.jllrealviews.com:

http://www.jllrealviews.com/viewpoint/gamification-getting-us-moving-workplace/

Oxford Dictionary. (2017, July 7). ethics. Retrieved from en.oxforddictionaries.com: https://en.oxforddictionaries.com/definition/ethics

Pianta, M. (1995). Technology and growth in OECD countries, 1970-1990. Cambridge Journal of Economics, 175.

Procopie, R., Bumbac, R., Giusca, S., \& Vasilcovschi, A. (2015). The Game of Innovation. Is Gamification a New Trendsetter? Economic, suppl. New Trends in Sustainable Business and Consumption, 1142-1155.

Pryor, M. G., Humphreys, J., Oyler, J., Taneja, S., \& Toombs, L. (2011). The Legitimacy and Efficacy of Current Organizational Theory: An Analysis. International Journal of Management, 209-228.

Purcell, K., \& Lee, R. (2014). Technology's Impact on Workers. PewResearchCenter.

Rapt. (2017, July 1). Deloitte. Retrieved from www.raptmedia.com: http://www.raptmedia.com/customers/deloitte/

Research Methodology. (2017, July 7). Purposive sampling. Retrieved from researchmethodology.net: http://research-methodology.net/sampling-in-primary-datacollection/purposive-sampling/

Rodrigues, L., Costa, C., \& Oliveira, A. (2016). Gamification: A framework for designing software in e-banking. COMPUTERS IN HUMAN BEHAVIOR , 620-634.

Rodríguez-muñoz, A., Sanz-vergel, A., Demerouti, E., \& Bakker, A. (2014). Engaged at Work and Happy at Home: A Spillover-Crossover Model. Journal of Happiness Studies, 271-283.

Ruhi, U. (2015). Level Up Your Strategy: Towards a Descriptive Framework for Meaningful Enterprise Gamification. Technology Innovation Management Review, 5-16.

Sarangi, S., \& Shah, S. (2015). Individuals, teams and organizations score with gamification: Tool can help to motivate employees and boost performance. Human Resource Management International Digest, 24-27. 
Saunders, A. (2016). 10 things that make you a bad boss - even if you think you are a good one. Management Today, 54.

Shpakova, A., Dörfler, V., \& MacBryde, J. (2017). Changing the game: a case for gamifying knowledge management. World Journal of Science, Technology and Sustainable Development, 143-154.

Sigala, M. (2015). The application and impact of gamification funware on trip planning and experiences: the case of TripAdvisor's funware. Electronic Markets, 189-209.

Silverman, R. E. (2011). Managing \& Careers -- Theory \& Practice: Latest Game Theory Mixes Work and Play. Wall Street Journal.

Sobocinski, M. (2017). I gamified my courses and I hate that... World Journal of Science, Technology and Sustainable Development, 135-142.

Spencer, R. W. (2013). Work Is Not a Game. Research Technology Management, 59-60.

Tansley, C., Hafermalz, E., \& Dery, K. (2016). Talent development gamification in talent selection assessment centres. European Journal of Training and Development, 490512.

The Center for Generational Kinetics. (2017, Feburary 2017). Generational Breakdown: Info About All of the Generations. Retrieved from genhq.com: http://genhq.com/faq-infoabout-generations/

Treuren, G. J., \& Halvorsen, B. (2016). The contribution of client embeddedness to an employee's employment experience. International Journal of Manpower, 989-1003.

University of Michigan . (2001). Collected Works of Abraham Lincoln. Volume 1. Ann Arbor, Michigan: University of Michigan Digital Library Production Services.

van der Meer-Kooistra, J., \& Vosselman, E. (2012). Research paradigms, theoretical pluralism and the practical relevance of management accounting knowledge. Qualitative Research in Accounting and Management, 245-264.

Vassileva, J. (2012). Motivating participation in social computing applications: a user modeling perspective. User Modeling and User - Adapted Interaction, 177-201.

Victoria University of Wellington. (2017, July 7). Human Ethics Policy . Wellington, New Zealand. 
Vinichenko, M. V., Melnichuk, A., Kirillov, A., Makushkin, S., \& Melnichuk, Y. (2016). Modern Views on the Gamification of Business. Journal of Internet Banking and Commerce, suppl. Special Issue: Finance, Services Sector and Commerce, 1-13.

Walton, N. (2017, July 7). What Is Research Ethics? Retrieved from researchethics.ca: https://researchethics.ca/what-is-research-ethics/

Werbach, K., \& Hunter, D. (2015). For the Win: How Game Thinking Can Revolutionize Your Business. Philadelphia, PA: Wharton Digital Press.

Whittington, J. L., \& Galpin, T. (2010). The engagement factor: building a high-commitment organization in a low-commitment world. The Journal of Business Strategy, 14-24.

Williams, J. R., \& Masuda, Y. (2016). A Measure Whose Time has Come: Formalizing Time Poverty. A Measure Whose Time has Come: Formalizing Time Poverty, 265-283.

Wilson, J. M. (2014). Henry Ford vs. assembly line balancing. International Journal of Production Research, 757-765 .

Xu, Y. (2011). Literature review on web application gamification and analytics. CSDL Technical report, 5-11.

Yee, N. (2007). Motivations for Play in Online Games . CyberPsychology \& Behavior, 772775.

Zichermann, G. (2012, December 10). The code of gamification ethics.

Zichermann, G., \& Linder, J. (2010). Game-based marketing: inspire customer loyalty through rewards, challenges, and contests. New York:: Wiley. 


\section{Appendix One: Interview Guide}

1. Hi. Firstly, I would like to thank you for attending the interview. As a researcher I want to know what experiences relating to gamification you have. But first I would like to begin by asking you to just go over your background?

2. How long have you worked at an organisation that has applied game principals?

3. Could you mention if there has been any game aspects like intangible privileges physical rewards, customisation or Leaderboards in a work context?

4. Did those applications result in a greater interest or more effort being put forward?

5. Do you think that there is some level of exploitation relating to game principals at work and why so you think this?

6. In general how do you think you act in a work environment using gamification?

7. Would you say gamification is more suited to younger workers or companies concerned with technology

8. What do you think of communication systems used in gamification?

9. Do you think co-workers that you have worked with share your overall feelings, in terms of what we have discussed today?

10. I appreciate the time you took for this interview. Is there anything else you think would be helpful for me to know? 


\section{Appendix Two: Email to Prospective Interviewees}

Hi, thank you for taking the time to open this email

I am a student conducting research towards the completion of a postgraduate degree in management, at Victoria University of Wellington. As part of my Master of Commerce (MCom) I would love to have participants for my study. The purpose of the study is to investigate how gamification impacts employee engagement.

It would be great if anyone who identifies as an employee working under a manager, could take part in a one-on-one interview for the research I will be conducting. However to be eligible you have to have been exposed, or are currently being exposed to gamification.

Gamification refers to the application of game-design principals and game elements in non-game contexts (i.e. leaderboards and incentives in the workplace), which in turn heavily emphasises rewards, clearly stated challenges, and scoring. With this in mind could you please indicate, as briefly as possible (i.e. one word answers), the following in the reply to this email

- If you have been, or are currently being exposed to gamification?

- If answered "yes" above, in which industry did you experience gamification?

- What industry do you work in presently?

- Your age

- Would you like to be interviewed?

If you would like to be interviewed please do the following task: HIGHLIGHT IN BOLD which one of the four options below appeals to you the most

1. Gaining recognition amongst colleagues (including key decision makers) by accomplishing more challenges or outworking co-workers

2. Working towards gaining more autonomy like free time (e.g. increased "break time")

3. Working towards the ability to reward other co-workers (e.g. unlocking the access of restricted workplace tools for others)

4. Gaining access to more social networking opportunities (e.g. attending or presenting at a conference)

Thank you for your time, it is truly much appreciated.

If you have any questions about this study and/or ethic queries, please contact the student researcher: Daniel McIntyre mcintydani2@myvuw.ac.nz, or supervisor: Dr Mohammad Saud Khan, (04) 463 6934, saud.khan@vuw.ac.nz, or Human Ethics Committee Convener:

Associate Professor Susan Corbett should participants have ethics enquires, +64-4-463 5480, susan.corbett@vuw.ac.nz. 


\section{Appendix Three: Information Sheet}

In-depth Interview Participation: How does gamification impact employee engagement?

\section{Information about the study}

I am a student conducting research towards the completion of a postgraduate degree in management, at Victoria University of Wellington. As part of my Master of Commerce (MCom) I am inviting you to participate in an in-depth interview. The purpose of the study is to investigate how gamification impacts employee engagement. Gamification refers to the application of game-design principals and game elements in non-game contexts (i.e. leaderboards in the workplace), which in turn heavily emphasises rewards, clearly stated challenges, and scoring.

This interview will involve meeting together to discuss ideas regarding gamification in the workplace. The interview will run for approximately 45 minutes to an hour. During the interview notes will be taken throughout.

\section{Your participation is completely voluntary and you may withdraw from this study two days prior to your interview.}

The interview will involve a device to record discussions. Only I will have access to the research materials collected during the interview. These materials will be stored securely in locked electronic and/or paper files (password protected), and will be destroyed within four years of the study. Participant identity will not be revealed to anyone outside of me. In the final research reports your opinions and ideas might be quoted directly for academic purposes, but no identifying details associated with these will be given.

This research has been approved by the Victoria University of Wellington Human Ethics Committee with the approval number: 0000023692

If you have any questions about this study and/or ethic queries, please contact the student researcher: Daniel McIntyre mcintydani2@myvuw.ac.nz, or supervisor: Dr Mohammad Saud Khan, (04) 463 6934, saud.khan@vuw.ac.nz, or Human Ethics Committee Convener: Associate Professor Susan Corbett should participants have ethics enquires, +64-4-463 5480, susan.corbett@vuw.ac.nz. 


\section{Appendix Four: Consent Form}

By signing this consent form, you are indicating that you fully understand information about the study, and have been given an opportunity to ask questions and have them answered to your satisfaction. Please remember that you do not have to answer a question if you don't want to. If you desire to withdraw please do so seven days prior to the interview taking place.

Please indicate your consent by ticking the following:

I consent to participate in the research

I agree to keep everything discussed confidential

I wish to receive a summary relating to findings

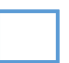

Participant's name:

Participant's signature:

Date:

\section{Researcher's Name: Daniel McIntyre}

Date:

If you have any questions about this study and/or ethic queries, please contact the student researcher: Daniel McIntyre, mcintydani2@myvuw.ac.nz, or supervisor: Dr Mohammad Saud Khan, (04) 463 6934, saud.khan@vuw.ac.nz. 
Appendix Five: Final Template Analysis Theme Hierarchy

\begin{tabular}{|c|c|}
\hline Theme & Location for hand written and typed notes \\
\hline $\begin{array}{l}\text { 1. The significant } \\
\text { impact of } \\
\text { management } \\
\text { actions }\end{array}$ & \\
\hline $\begin{array}{l}\text { 2. } \text { Gamification } \\
\text { techniques and } \\
\text { their impact }\end{array}$ & \\
\hline $\begin{array}{l}\text { 3. Self-determination } \\
\text { theory and } \\
\text { psychological } \\
\text { needs in relation to } \\
\text { gamification } \\
\text { techniques }\end{array}$ & \\
\hline $\begin{array}{l}\text { 4. Player-types of } \\
\text { interviewees and } \\
\text { the impact of } \\
\text { different motives }\end{array}$ & \\
\hline $\begin{array}{l}\text { 5. The minimal } \\
\text { alignment with } \\
\text { generations an } \\
\text { industries }\end{array}$ & \\
\hline $\begin{array}{l}\text { 6. Potential } \\
\text { Installation } \\
\text { guidance for } \\
\text { managers }\end{array}$ & \\
\hline $\begin{array}{l}\text { 7. The little relevance } \\
\text { to gamified } \\
\text { software and tech }\end{array}$ & \\
\hline
\end{tabular}


